\title{
LA ACTUACIÓN EN PREHISTORIA DE JOSÉ MIGUEL DE BARANDIARÁN
}

\author{
PREHISTORIC RESEARCH BY JOSÉ MIGUEL DE BARANDARIÁN
}

\author{
por \\ IGNACIO BARANDIARÁN
}

RESUMEN Se evalúan los trabajos de campo y las publicaciones del etnólogo y prehistoriador J.M. de Barandiarán (1889-1991). Sus prospecciones y excavaciones arqueológicas cubren medio siglo de aportaciones, descubriendo datos de especial importancia para el conocimiento de la Prehistoria vasca, sobre todo yacimientos del Paleolítico y monumentos megalíticos.

En esta revisión historiográfica se recuerdan sus relaciones profesionales, se destaca la "modernidad" de su metodología de recogida de datos y se señala su protagonismo en la coordinación de una "escuela" actual de prehistoriadores de solvencia.

ABSTRACT This paper outlines a historiographic assessment of both fieldwork and publications by Ethnologist and Prehistorian J.M. de Barandiarán (1889-1991). His archaeological surveys and excavations spanned half of a century and produced a mainstream for the knowledge of Vasque Prehistory, mainly on Paleolithic and Megalithic cultures. His professional relations are recalled, as well as the modernity of his data recording methods, thus underlining his protagonism in the emergence of a consistent school of prehistorians.

\section{PRESENTACión}

Los datos básicos (en localizaciones y materiales) que estructuran el conocimiento de la Prehistoria occidental se han ido reuniendo en la primera mitad de este siglo. En buena parte los aportaron la tenacidad e inteligencia de la investigación regional que, con no muchos medios, prospectó, excavó y publicó importantes yacimientos.

Pretendo recordar aquí el protagonismo excepcional desempeñado por José Miguel de Barandiarán (18891991) en el conocimiento concreto de la Prehistoria del País Vasco; y, a más amplio alcance, evaluar su contribución al progreso general de la disciplina que en esas décadas define sus objetivos propios y consolida su método ${ }^{\prime}$.

1. Dentro del Curso del Verano de 1992 de la Universidad del País Vasco sobre "La obra de D. José Miguel de Barandiarán", que coordinó J. Altuna, acepté el difícil compromiso de ofrecer el 3 de setiembre de 1992 una evaluación 
La historia de las investigaciones sobre la Prehistoria vasca se organiza en cinco etapas. La primera, de iniciación, que culmina con los importantes trabajos de E.Passemard al norte del Pirineo, llega hasta 1917. La segunda, de consolidación y madurez, cubre un par de decenios hasta 1936, siendo protagonizada casi exclusivamente por los trabajos de T. de Aranzadi, J.M.de Barandiarán y E.de Eguren. La tercera, de transición hasta mediada la década de los 50 , en que casi todo se paraliza. La cuarta, de continuidad con J.M.de Barandiarán, en que él reanuda las excavaciones, acogiendo en su equipo a quienes en la segunda mitad de los 60 se irán haciendo cargo de las investigaciones en las diversas provincias o especialidades. Y la quinta, de la actualidad, a partir de avanzados los 70, cuando se multiplican los equipos a partir de los inmediatamente formados con J.M. de Barandiarán y surgen otros dependientes o no de ellos. De ese modo, cuantos han analizado el desarrollo de los estudios de Prehistoria en esta parte del Sudoeste europeo reconocen que la intervención de J.M. de Barandiarán los hizo pasar de un estadio inicial, en que se disponía de conocimientos poco articulados sobre datos muy aislados, a la etapa de madurez y desarrollo actual de esas investigaciones.

J.M.de Barandiarán dedicó cerca de setenta y cinco años de su vida al estudio del tiempo pasado en el País Vasco, rastreando sus restos más antiguos (de la Prehistoria) y el saber popular (las opiniones, mitos y tradiciones que estudia la Etnografía). Su obra acumuló millares de referencias recogidas en excavaciones arqueológicas o en encuestas orales, conservadas hoy en museos y publicadas en un conjunto de textos que llenan veintidos gruesos volúmenes en la edición de sus obras completas; es punto de referencia inevitable para cualquier investigación sobre los grupos humanos que ocuparon en el pasado este territorio ${ }^{2}$.

En su actuación arqueológica destaca, en primer lugar, su continuada labor de campo, descubriendo y

sobre lo que supuso esa obra científica en el contexto de las investigaciones prehistóricas de su tiempo. Según el programa establecido, tras esta lección de introducción global se analizó su contribución al conocimiento de las sucesivas etapas de la Prehistoria vasca (el Paleolítico por A Baldeón, el Neolítico y la Edad del Bronce por A. Armendáriz, la Edad del Hierro por A. Llanos y el arte prehistórico por J.M. Apellániz) y de la Etnografía (por A. Manterola, G. Arregui, J.M. Apalategui, J. Garmendia y J.M. Satrústegui). Inédito hasta hora, ofrezco aquí el texto fundamental de mi contribución a ese Curso, con algunas anotaciones complementarias.

2. La serie de las Obras completas de J.M.de Barandiarán (Editorial La Gran Enciclopedia Vasca, Bilbao) comprende veintidos volúmenes, publicados entre 1972 y 1984, con un total de diez mil páginas que se distribuyen en: textos de Etnología/Etnografía (el volumen 1 con el "Diccionario de Mitología Vasca" de 450 páginas, los volúmenes 2 a 6 y 21 de monografías diversas con 2.904 páginas, y los volúmenes 18 a 20 con el estudio de las estelas de 1.128 páginas), Arqueología (fundamentalmente prehistórica, en los volúmenes 7 a 17 con 5.156 páginas) y misceláneos (el volumen 22 ).

Conviene - para conocimiento del lector de estas páginas - aclarar el sentido y uso que se hará en el texto al referente 'País Vasco' (o 'Vasconia' o 'Euskal Herria', en denominaciones prácticamente sinónimas) como término que en el sentimiento de muchas gentes de esta tierra, y al margen de la situación administrativa actual y de su dependencia histórica (decididas hoy entre una Comunidad Autónoma del País Vasco y una Comunidad Foral de Navarra en el Estado español y buena parte del Departamento de Pirineos Atlánticos en el Estado francés), engloba a territorios ubicados a ambos lados del Pirineo (al sur, las provincias de Vizcaya, Alava, Guipúzcoa y Navarra; al norte, las de Laburdi, Baja Navarra - Ultrapuertos - y Zuberoa) que participan de una comunidad lingüística y de diversos rasgos antropológicos de origen muy antiguo. En este sentido (así como con los otros sinónimos aproximados 'Pirineo occidental' o 'Pirineo vasco') se empleó en la obra de J.M.de Barandiarán.

La historiografía de la Prehistoria europea conoce numerosos casos, como el de J.M.de Barandiarán, de densos estudios locales desarrollados por investigadores que optaron por una escala espacial concreta (lo 'regional'), sea por la comodidad y accesibilidad del conocimiento de lo más próximo o por el ánimo de una normal afección por su tierra. En alguna valoración de esas aportaciones científicas se suelen reducir las inquietudes y aportación de los investigadores a los límites de un tiempo o escuela concretos, simplificando excesivamente las calificaciones. Con ligereza se han alineado en el 'nacionalismo' o en el 'regionalismo' - como determinante de algo restrictivo o mediatizado y con cierto matiz peyorativo - aportaciones del primer tercio de este siglo que alcanzaron conclusiones positivas depuradas y notablemente objetivas. 
excavando muchos yacimientos; y la aportación, después, de un sólido argumento de interpretación conjunta de las evidencias.

a. Intervino primero, en equipo con T.de Aranzadi y E.de Eguren, a partir del verano de 1917 y hasta el inicio de la guerra civil española, en julio de 1936, en excavaciones de importantes cuevas ocupadas en el Paleolítico superior de Vizcaya y Guipúzcoa y en el descubrimiento y estudio de estaciones dolménicas de Guipúzcoa, Navarra y Alava.

Telesforo de Aranzadi (Vergara 1961 - Barcelona 1945), Doctor en Ciencias Naturales (en 1888) con una tesis de Antropología de la población vasca, fue Catedrático de las Universidades de Granada (de Mineralogía y Zoología entre 1895 y 1899) y de Barcelona (de Botánica descriptiva entre 1899 y 1920 , y de Antropología entre 1920 y 1931); Enrique de Eguren (Vitoria 1888 - Oviedo 1944), Doctor en Ciencias Naturales (en 1913) con una tesis sobre Antropología y Prehistoria vasca, fue Catedrático de la Universidad de Oviedo (de Mineralogía y Botánica entre 1915 y 1923, y de Biología y Geología entre 1923 y 1944). El equipo formado por Aranzadi, Barandiarán y Eguren supuso en la ciencia peninsular de esos años una garantía de honestidad y de seriedad científicas: pues, como justamente se ha afirmado (Elósegui 1948: 54), "eran hombres competentes y experimentados, bien provistos de conocimientos de Prehistoria, Antropología y Ciencias Naturales, que estuvieron constantemente en contacto con especialistas diversos nacionales y extranjeros y con gentes de laboratorio".

Se han destacado (Apellániz 1974: 8-9) en este período de investi-gaciones 1917-1936 de la Prehistoria vasca varias innovaciones con respecto a lo precedente: " intervienen por primera vez en la excavación de los yacimientos personas especializadas en Arqueología y Etnografía y de formación universitaria y docente ...los cuales lograron unir los aspectos arqueológicos, etnográficos y antropológicos de la Prehistoria ...las excavaciones se suceden con frecuencia a los descubrimientos, lo cual hace de este período un tiempo especialmente fecundo... esta fecundidad se ve coronada por la aparición de una teoría general acerca del País Vasco".

b. Se dedicó luego J.M. de Barandiarán solo, en los años 1937 a 1953 de su exilio, especialmente a estudios sobre las costumbres funerarias tradicionales y, en lo que respecta a la Arqueología, a la prospección de sitios de la Prehistoria avanzada del lado norte del Pirineo (en las provincias de Zuberoa, Laburdi y Ultrapuertos).

c. Posteriormente, en los veinte años que median de 1954 a 1974, dirigió las excavaciones de buenos yacimientos prehistóricos de Guipúzcoa, Alava y Vizcaya, acogiendo en su equipo a varios de los que pronto asumiríamos la continuación de las investigaciones. A partir de esa generación de discípulos se han ido constituyendo otros tantos grupos de trabajo independientes de los que han surgido nuevas promociones que continúan hoy con esas líneas de estudio. La mayoría de quienes ahora trabajamos en la Prehistoria del Pirineo occidental y zonas limítrofes reconocemos en J.M.de Barandiarán al que fue, con su metodología e inquietudes, el principal promotor de estos estudios en el primer cuarto del siglo, haciéndoles alcanzar su actual estado de madurez.

Antes de cualquier consideración sobre su obra, se debe declarar que los que le hemos conocido y tratado con asiduidad le recordamos como modelo de una vida intensamente dedicada al conocimiento, paciente en el trato y tolerante con todos. Además, cuantos nos dedicamos a la Arqueología o a la Etnografía le debemos un impresionante caudal de datos imprescindibles para comprender la situación cultural de quienes en el pasado tradicional inmediato o prehistórico poblaron la zona pirenaico-occidental.

La biografía de J.M.de Barandiarán ofrece un ejemplo excepcional de tenacidad intelectual para reconocer las señas de identidad de lo vasco; se plasmó en sus actividades docentes y de divulgación y en la ingente masa de datos recuperados tanto como en las interpretaciones que los explican. 
Con motivo de su fallecimiento el 21 de diciembre de 1991, los medios de comunicación pusieron de relieve el valor de su obra de investigación, el ejemplo de su vida y la importancia de su magisterio para con la cultura vasca en general: "investigador valiente y moderno, constante, callado y serio en búsqueda de resultados reales, sólidos y fundamentales, frente a lo que impera ahora que es la apariencia de los balances momentáneos sobredimensionados de cara a la galería sin contenidos reales ni fundamentos sólidos o permanentes" (editorial de "El Mundo": 22.XII.1991).

Como preámbulo y excusa de estas reflexiones, he de advertir:

- En primer lugar, que no es sencillo delimitar precisamente el 'tiempo' al que se debe adscribir - y por tanto el contexto concreto en el que evaluarla - la obra de un científico, pues su referente nunca puede ser el marco definido por las fechas de edición de una obra impresa sino los perfiles cronológicos nada exactos del ambiente intelectual en que se desarrollaron sus pesquisas con referencia a unas determinadas generaciones intelectuales, tendencias o escuelas. Dificultad que se agudiza cuando nos enfrentamos a una obra tan dilatada en el tiempo como la que llevó a cabo en Prehistoria José Miguel de Barandiarán, a lo largo de sesenta años, entre 1916 y avanzada la década de los 70: es decir, durante el prolongado proceso de maduración de esa Ciencia en el que varias generaciones de estudiosos y distintas actitudes teóricas, metodológicas y de intereses han ido sucediéndose. Me ceñiré en este texto fundamentalmente a la consideración de la primera etapa de sus aportaciones, de 1917 a 1936, cuando trabaja frecuentemente en equipo con T. de Aranzadi y con E.de Eguren, y, de modo complementario, al período en que, tras la guerra civil y vuelto de su exilio, reanuda los trabajos de campo, en la segunda mitad de los años 50 y durante los 60 .

- En segundo lugar, que, teniendo en cuenta la afección personal que me une con el personaje y la obra examinados, se puede dudar de que se haya salvado la necesaria objetividad del empeño evaluador. En mi descargo apuntaré la existencia de tres factores que favorecen notablemente un juicio más afinado. A saber: la distancia efectiva de casi veinticinco años que ya media entre el fin de las actividades de Barandiarán en Prehistoria y el momento en que nos enfrentamos con la responsabilidad de juzgarlas; la existencia de valoraciones ajenas producidas por quienes han historiado el progreso de esta Ciencia en Europa Occidental; y, muy en concreto, las revisiones minuciosas a que los textos y colecciones aportados por él han sido, y están siendo, sometidos con motivo de su utilización para la elaboración de trabajos de revisión sistemática de la Prehistoria de esta parte del Continente (cerca de una veintena de tesis doctorales, por ejemplo, entre otros).

- En tercer lugar, que no resulta nada fácil evaluar desde la perspectiva del tiempo presente el conjunto de una obra científica tan densa y dilatada en el tiempo ni el detalle de sus investigaciones concretas en un momento determinado. Aquellas aportaciones, que de hecho culminaron hace algún tiempo (y son, en ese sentido, 'hijas de su época'), no pueden ser, sin riesgo de incurrir en evidente injusticia, sometidas ahora a juicio de valor formulado desde la más cómoda posición crítica de la Arqueología de hoy: porque participamos de preocupaciones metodológicas o teóricas diferentes a las que impulsaron los estudios prehistóricos de hace unas décadas y disponemos de recursos que pueden ser bastante más eficaces que los que estuvieron a su alcance.

Para intentar una evaluación aproximada de lo que la obra científica de José Miguel de Barandiarán supuso en el contexto de las investigaciones prehistóricas de su tiempo disponemos de varias fuentes de información.

a. Primeramente, y como base fundamental de referencia para cualquier evaluación de una actividad científica, se hallan los resultados inmediatos dẹ su trabajo: las colecciones de elementos que recuperó y se conservan en los museos públicos y los textos en que ofreció esos datos y sus interpretaciones. De gran 
provecho resulta la lectura de sus memorias de excavación y de sus obras de síntesis: en ellas queda constancia de las autoridades que usa y le sirven de refrendo/comparación en sus asertos y determinaciones, de los conocimientos y opiniones de que participa y de las preocupaciones a las que responde su obra. Más aún, el estado de conservación actual de las colecciones que Barandiarán aportó a la Prehistoria del Pirineo occidental y el contenido de sus memorias de excavación pueden ser muy provechosamente, para él, cotejadas con los materiales y textos que por entonces aportaban otros prehistoriadores.

b. Luego, debemos acudir a otros documentos más personales que muestran sus opiniones y relaciones científicas: sus diarios, que, a falta de edición completa, conocemos a través de la consulta, extracto y glosa de su biógrafo (L.de Barandiarán 1976 y 1992) y la correspondencia que J.M.de Barandiarán recibió en la etapa 1915-1936 (bien editada por L.de Barandiarán 1989; que se completa con una segunda entrega, de la correspondencia del período 1952-1991, en L.de Barandiarán 1995).

c. Además hay que conocer y contrastar las opiniones de quienes, ciertamente no demasiados ni con todo el detalle que ahora nos interesa, hayan escrito sobre su producción científica, valorando su aportación a etapas concretas del desarrollo de la Prehistoria o su metodología. Algunos de esos textos se han publicado en obras colectivas de homenaje a Barandiarán: como las promovidas por la Diputación de Vizcaya, la Sociedad de Ciencias Aranzadi, el Instituto Alavés de Arqueología, la Sociedad de Estudios Vascos, la Universidad de Navarra y otras entidades (V.V.A.A. 1964, 1971, 1978, 1979, 1980, 1990 y 1992). Otros responden a una intención historiográfica o biobibliográfica más concreta: así los de E.Vallespí (1966 y 1975), J.M.Satrústegui (1980), I.Barandiarán (1980, 1988 y 1992) o A.Manterola (1984).

d. Complementariamente, hubiera sido de indudable utilidad disponer de los catálogos de las bibliotecas que Barandiarán tuvo a su disposición en los años de iniciación y desarrollo de sus estudios sobre la Prehistoria vasca: la suya particular y las de las instituciones en las que trabajó (como las del Seminario Conciliar de Vitoria, de Ikuska o de la Sociedad de Estudios Vascos, las de los museos próximos tanto como de los centros extranjeros que visitó, etc.). Empresa difícil de llevar adelante, si no imposible en todos sus extremos.

e. Con esos datos y bastantes impresiones (producidas en los años de conocimiento y colaboración con J.M.de Barandiarán) he organizado este tema de reflexión, en el que se examinarán dos cuestiones complementarias: por una parte, el estado de la Prehistoria en las décadas anteriores al comienzo de la guerra civil española y las relaciones profesionales de Barandiarán con los investigadores de su tiempo; por otra, el valor de su obra en ese contexto temporal, tanto en lo que atañe a metodología y principios de la recogida de los datos como a su interpretación.

\section{EL PANORAMA DE LA PREHISTORIA OCCIDENTAL EN EL TIEMPO DE J.M. DE BARANDIARÁN}

De modo habitual se han distinguido (L.Pericot 1968, refiriéndose al estudio del Paleolítico) tres etapas fundamentales en la historia de las investigaciones sobre la Prehistoria peninsular: la primera, de iniciación, hasta 1914; la segunda, de maduración/consolidación, de 1914 a 1936; y la tercera, a partir de 1940. Coincide básicamente tal periodificación con la apreciada en la historia de estos estudios a escala territorial mayor, en el conjunto de Europa occidental.

En la historiografía de la Prehistoria vasca (por ejemplo I.Barandiarán 1967: 13-25; J.Altuna 1972: 5-8 o J.A. Mujika 1985: 20-32) se han individualizado dos etapas más a partir de la tercera señalada por L.Pericot: una cuarta, de 1953 a 1967, en que J.M.de Barandiarán, vuelto del exilio, reinicia los trabajos de campo en estas provincias y asegura la continuidad de los trabajos interrumpidos por la guerra civil de España y la 
segunda guerra mundial; y una quinta, de 'actualidad', a partir de 1967/1970. En esas etapas segunda (en que se consolidan tales investigaciones adquiriendo entonces un fuerte capital de datos) y cuarta (en que se asegura la transición a los grupos que actualmente llevan adelante la mayor parte de los estudios de Prehistoria) ejercerá J.M.de Barandiarán un protagonismo destacado, buscando y excavando yacimientos muy significativos y dirigiendo equipos de trabajo.

\section{a. La primera década del siglo}

En último cuarto del siglo XIX y los primeros años del XX la Prehistoria adquiere su estatuto propio entre las varias disciplinas que se dedican al conocimiento de las culturas del pasado. Se perfila la Prehistoria mediante la rápida acumulación de una nutrida serie de hallazgos y determinaciones arqueológicas, madurando así la que hasta entonces era una mera ciencia de las antigüedades o de la cultura primitiva arcaica esbozada por los anticuaristas pioneros de la segunda mitad del XIX. Obviamente, se despliega en este tiempo una producción bibliográfica específica, aunque de intención y contenido heterogéneos (tanto a través de las revistas que van apareciendo como en volúmenes exentos), numerosa en títulos que consulta una ávida clientela de aficionados y eruditos.

En esta primera década del siglo se producen aportaciones tan importantes para la Prehistoria occidental como las de las excavaciones de los sitios franceses de Le Moustier, La Chapelle-aux-Saints, La Quina o La Ferrassie, el descubrimiento y estudio de los restos de Mauer o el reconocimiento del arte rupestre paleolítico (con, p.e., el hallazgo en 1901 de los 'santuarios' de Font-de-Gaume y Combarelles). Por entonces, también, se están editando los textos básicos para la comprensión del entramado general de la cultura y ambiente prehistóricos; como los de M.Boule (de 1906) sobre antropología prehistórica, los de A. Penck y E. Brückner (de 1901 a 1909) sobre los ciclos climáticos alpinos y las glaciaciones, o los primeros cuadros fundamentales de H.Breuil sobre periodificación del arte (de 1906) y las subdivisiones del Paleolítico Superior (de 1912).

En la Prehistoria peninsular es en esta década cuando los iniciadores de las investigaciones (como J.Vilanova y Piera, A.Viana, L.Siret,...) están siendo relevados por una nueva 'generación' de prospectores e investigadores.

Destacaremos en la crónica de la Prehistoria cantábrica (véase, por ejemplo, lo que de ella refiere B.Madariaga 1975: 11-32) unos hitos muy significativos de esta etapa de incremento de datos: en 1902, tras su reconocimiento por E. Cartailhac, el inicio con H.Breuil del estudio sistemático del arte de Altamira; las prospecciones de eruditos locales como H.Alcalde del Río (en 1903 descubre los yacimientos de Hornos de la Peña y del Castillo, en 1905 el del Valle) o L.Sierra; el patrocinio desde 1906 del Principado de Mónaco en la promoción y subvención de las investigaciones de campo en diversos sitios de la provincia de Santander, constituyéndose en 1910 el Institut de Paléontologie Humaine que subvenciona las excavaciones de Hornos de la Peña, El Valle y, sobre todo, El Castillo (de 1910 a 1914); un nutrido despliegue de prospecciones, sondeos y excavaciones (como el descubrimiento en 1911 por H.Obermaier y P.Wernert de La Pasiega, o las excavaciones de J. Carballo y W. Beatty en El Pendo en 1910 y Morín en 1911); o la publicación en 1911 por E.Harlé de su catálogo de fauna del Cuaternario. En otras zonas peninsulares es en ese tiempo cuando, por ejemplo, se producen el descubrimiento y primeros estudios sobre al arte rupestre levantino (en 1903 en la Roca dels Moros de Calapatá, en 1907 en Cogul), tienen lugar los trabajos del Marqués de Cerralbo en varias estaciones prehistóricas de la Meseta tan importantes como el depósito paleolítico de Torralba (en 1907) o el conjunto campaniforme de Somaén (en 1909), se investigan en Cataluña los sitios de Bañolas, Capellades (abrigos Agut y Romaní por L.M. Vidal) y Seriñá (en 1908 por M.Cazurro) y se excavan varias interesantes cuevas del Paleolítico andaluz (como las de Murciélagos, Vermeja y otras por L.Siret o cueva Ambrosio, donde practicaron sondeos en 1913 H. Breuil y F. de Motos). 
En el País Vasco son éstos los años en que A.de Gálvez Cañero va localizando yacimientos prehistóricos en varias cuevas vizcaínas, comienzan las prospecciones de E. de Eguren en 1913 en Alava, T de Aranzadi inicia sus excavaciones en megalitos guipuzcoanos (con P.M.Soraluce desde 1909) y navarros (con F.de Ansoleaga, desde 1913) y se desarrollan los trabajos sistemáticos de E. Passemard en la vertiente septentrional del Pirineo, con sondeos en la cueva de Lezia (1912) y con las excavaciones de Olha I y de Isturitz (a partir de 1913). También por entonces se organizan los lotes de Prehistoria entre los de Antigüedades que se custodian en colecciones y museos públicos (como el museo de la Cámara de los Comptos Reales de Navarra que se inaugura en 1910, el 'Museo incipiente' de Vitoria, el Municipal de San Sebastián,...) o se van publicando listas e informes de materiales incorporados en los Boletines de las correspondientes Comisiones provinciales de Monumentos Históricos y Artísticos (como en los de Vizcaya y de Navarra de $1910,1911, \ldots)$.

\section{b. Los años 1914 a 1936}

En ellos se consolida la Prehistoria occidental como Ciencia. En la historiografía de la Prehistoria viene esta etapa precedida por la de los pioneros, al ir, por ejemplo en el sudoeste de Francia, dejando paso las investigaciones de E.Lartet, G.y A.de Mortillet, E.Piette o E.Cartailhac al trabajo magistral de J.Bouyssonie, H.Breuil, D.Peyrony o H.Bégouën. Y precede, a su vez, a la etapa que supuso en las décadas inmediatas siguientes, por el forzoso paréntesis de la guerra civil española y de la segunda guerra mundial prolongadas en las lógicas circunstancias adversas de lo postbélico, un relativo estancamiento de esos estudios.

En el período de madurez 1914-1936 alcanza la Prehistoria peninsular un reconocimiento público de su interés y aporta un buen caudal de descubrimientos, excavaciones y estudios monográficos que la estructuran; es el tiempo en que la obra científica de J.M.de Barandiarán se desarrolla con intensidad.

Se produce en esta época la creación de organismos públicos que promueven y subvencionan las excavaciones, se cuidan de custodiar las colecciones y patrocinan la publicación de los estudios. Se formula la primera Ley de Excavaciones de España (promulgada el 7 de julio de 1911 y desarrollada en Reglamento el 1 de marzo de 1912) que ampara y regula las concesiones de los trabajos arqueológicos de campo e interviene, como su organismo gestor, la Junta Superior de Excavaciones y Antigüedades que publica entre 1915 y 1935 ciento treinta y seis memorias de excavaciones y estudios. Van surgiendo varias instituciones de promoción de las investigaciones, mediante equipos y laboratorios bien dotados: como es el caso, entre otros, de la Comisión de Investigaciones Paleontológicas y Prehistóricas (dependiente de la Junta de Ampliación de Estudios y con sede en el Museo Nacional de Ciencias Naturales, de Madrid) que se crea en 1913 y actuará hasta 1936, del Servicio de Investigaciones Arqueológicas del Institut d'Estudis Catalans a partir de 1914, de la Sociedad de Estudios Vascos que se funda en 1918 (con el patrocinio de las Diputaciones de Alava, Vizcaya, Guipúzcoa y Navarra) o del Servicio de Investigaciones Prehistóricas de la Diputación de Valencia que surge en 1927.

En ese mismo tiempo la Prehistoria se incorpora formalmente a los planes de estudios universitarios en los dos centros donde, precisamente, desarrollan sus investigaciones y docencia quienes mantienen una excelente relación científica con J.M. de Barandiarán: la Universidad Central, de Madrid, de cuya Cátedra de Historia Primitiva del Hombre era titular desde 1922 Hugo Obermaier, y la Universidad de Barcelona donde ejerce docencia Pedro Bosch Gimpera (Catedrático desde 1916 de Historia Antigua y Media, director de su Seminario de Prehistoria desde 1917 y Catedrático de Prehistoria e Historia Antigua desde 1930). A ellos se deben los completos estados de la cuestión de la Prehistoria peninsular en su contexto, con síntesis de calidad excepcional: El Hombre Fósil (en sus dos ediciones de 1916 y 1925), Fossil Man in Spain (1924) y El hombre prehistórico y los orígenes de la humanidad (1932) de Obermaier, y Prehistoria Catalana (1920), El problema etnológico vasco y la Arqueología (1922) y Etnología de la Península Ibérica (1932) de Bosch Gimpera. 
En Asturias el inicio del conocimiento arqueológico de los yacimientos paleolíticos tiene como protagonistas a E.Hernández Pacheco (con sus trabajos de excavación de la cueva de La Paloma y el estudio del arte parietal de la Peña de Candamo y al Conde de la Vega del Sella que se dedica a un trabajo intenso ejemplar excavando, entre otros sitios, Cueto de la Mina (a partir de 1914), La Riera, Balmori y los del complejo Asturiense y estudiando los grabados rupestres del Buxu con H.Obermaier. En la provincia de Santander, suspendidas con el comienzo de la primera guerra mundial las actividades del Institut de Paléontologie Humaine, experimentan las investigaciones de campo una evidente detención (tal como ha apuntado M.R. González Morales 1991: 18-19), salvadas las prospecciones de H.Alcalde del Río, que van disminuyendo, la actuación no muy aceptable de J.Carballo (con sus "descripciones pintorescas" en expresión de González Morales), el importante trabajo de excavación de H.Obermaier en Altamira (en 1924 y 1925) y sus prospecciones (que quedaron prácticamente inéditas) en la cueva del Rascaño. En Cataluña y el Levante tienen lugar en estas dos décadas trabajos de campo que protagonizan diversos equipos que coordina P.Bosch Gimpera y dirigen J.Colominas, J.de C. Serra Ráfols, L.Pericot (en dólmenes catalanes o en la excavación, de 1928 a 1931, en la cueva del Parpalló) o S.Vilaseca (que, en 1930, empieza a excavar San Gregori de Falset) y otros interesados (como quienes se integran en el grupo local del Bajo Aragón, por citar uno de los más significados). De especial relevancia es el trabajo que en la comarca de Solsona lleva a cabo a partir de 1917 J.Serra Vilaró, identificando y excavando numerosas cuevas y dólmenes (cerca de ciento cincuenta sepulcros megalíticos) y aportando las provechosas monografías de síntesis El vas campaniforme a Catalunya (en 1923) y La civilització megalitica de Catalunya (en 1926). Son esos mismos los años, por cerrar esta selección de elementos significativos de la madurez de la Prehistoria peninsular, en los que H.Obermaier y J.Pérez de Barradas desarrollan sus investigaciones sobre el Paleolítico de las terrazas del Manzanares y en que D.A.E.Garrod (en 1926) excava el yacimiento gibraltareño de Devil's Tower.

En resumen, esta etapa de madurez de la Prehistoria de la Península Ibérica, en la que encaja muy precisamente la actuación de Aranzadi, Barandiarán y Eguren, ofrece unas características comunes a lo que se estaba produciendo entonces en el resto de Europa. A saber:

1. La intervención de auténticos especialistas, con subvenciones relativamente suficientes aportadas por instituciones consolidadas de investigación.

2. El interés por la recogida directa (y no tanto por el estudio de colecciones reunidas por otros) de datos en los yacimientos, en cuyos niveles se intenta reconocer y afianzar el marco teórico de las periodificaciones que entonces mismo estaban acabándose de perfilar.

3. El desarrollo de un método propio de la excavación en Arqueología prehistórica, con insistencia en el control de las secuencias estratigráficas, en la cartografía de los depósitos y en la recuperación de elementos del contexto (fauna o sedimentos), despegándose tanto del coleccionismo que había imperado décadas antes como del modo habitual de excavar en los yacimientos de la Arqueología clásica.

4. La preocupación por ir marcando algunas prioridades de la investigación, especializándose los estudiosos y los equipos, y por asegurar una rápida publicación de los resultados a través de un tipo de memoria de contenido y desarrollo bastantes homogéneos.

5. Una pretensión didáctica bastante generalizada que atiende a la divulgación de los resultados, mediante su exposición en los museos, ciclos de conferencias o la publicación de obras de síntesis de destino 'popular'.

6. En una perspectiva teórica, hay un notable arraigo de las opiniones y sistemas de investigación del historicismo cultural, más o menos directamente derivado de la Escuela de Viena. De ahí la preocupación de muchos prehistoriadores de entonces por determinar la tipología formal del bagaje cultural y sus variantes en tiempo y espacio, definir las áreas genéticas y de difusión de esas variantes culturales, determinar los elementos de continuidad en las diversas áreas y las causas y mecanismos del cambio y articular referencias etnográficas y arqueológicas en un discurso coherente sobre las formas de vida de los "primitivos", en lo que se refiere al arte y lo simbólico, las técnicas y las actividades. Una lectura detenida de las grandes obras de 
síntesis de la época ${ }^{3}$ revela su interés por determinar las líneas de continuidad cultural y las relaciones entre las diversas áreas y por aplicar los criterios de interpretación del método históricocultural al reconocimiento de esas áreas y de su entronque en el tiempo.

\section{c. La transición al tiempo actual, de 1940 a 1969}

Los conflictos bélicos inmediatos (la guerra civil de España y la segunda guerra mundial) provocarán una quiebra de la mayor parte de las líneas de investigación vigentes, durante un lapso de tiempo más o menos dilatado hasta que se recuperen los impulsos, preocupaciones y equipos de aquella precedente etapa de madurez. Así la historiografía de este período ofrece, primero, unos años de paralización de las actividades; y, de seguido, el inicio de un despegue del conocimiento protagonizado por quienes han asegurado la transición al momento actual, empalmando generaciones de investigadores.

En lo que afecta más directamente a la Prehistoria peninsular se debe recordar la ausencia de los dos principales impulsores (Bosch Gimpera y Obermaier) de los grupos relacionados con las universidades de Barcelona y Central, la supresión por decreto de varias instituciones de mucha importancia (como la Junta de Ampliación de Estudios - que es sustituída por el Consejo Superior de Investigaciones Científicas, de vida bastante lángida en lo que a Prehistoria se refiere durante algún tiempo -, la Sociedad de Estudios Vascos o el Institut d'Estudis Catalans), la dispersión de varios de los equipos que hasta entonces habían protagonizado los trabajos de campo, o la drástica limitación de muchas posibilidades de relacionarse con los centros de investigación de allende los Pirineos.

Examinando el ejemplo particular del Paleolítico de la región cantábrica, el caso excepcional del ambicioso (y, en buena parte, frustrado) proyecto del Pendo, entre 1953 y 1957 (en el que intervinieron como directores de la excavación A.Cheynier y A.Leroi-Gourhan, y equipos bien preparados en ciencias auxiliares), programado por J.Martínez Santaolalla y que pretendía vertebrar una 'escuela de prehistoria', es una excepción de abundancia de medios en un contexto de penuria material. Por entonces varios arqueólogos iban venciendo con admirable aporte de entrega personal esa escasez de recursos o de apoyo institucional: son los que algunos han llamado los prehistoriadores de la transición, a los que se debe el mérito de haber sabido introducir una metodología moderna en el estudio del Paleolítico peninsular.

Convendrá, para nuestro propósito de encuadrar y contrastar la obra científica de Barandiarán en su tiempo, señalar algunas notas de la etapa de transición hacia la actualidad (en las dos décadas que siguen al final de la guerra civil).

Discurriendo los 40 , empiezan a relanzarse las excavaciones y las publicaciones sobre Prehistoria. Discípulos y antiguos colaboradores de los prehistoriadores de primera línea de antes de la guerra establecen los nexos de continuidad con las investigaciones precedentes: así ocurre, por ejemplo, en torno al Museo Arqueológico de Barcelona, al Servicio de Investigación Prehistórica de la Diputación de Valencia o a las Cátedras de Prehistoria de la Universidad de Barcelona y de Historia Primitiva del Hombre de la Universidad Central de Madrid. Mientras que la organización de unas Comisarías de Excavaciones pretende encauzar los trabajos de campo a nivel de todo el Estado y bastantes instituciones provinciales (sean los museos o las diputaciones, con sus servicios específicos que se están creando) se harán cargo de su animación y subvención. A lo largo de

3. Por ejemplo aquellos que en ese tiempo constituyen libros de consulta imprescindible para los especialistas, como Les religions de la Préhistoire. Paleólithique (1921) de Th.Mainage, Kunst und Kultur des Vorzeit Europas. I. Das Palaeolithikum (1929) de H. Kühn, El hombre prehistórico y los orígenes de la humanidad (1932) de H. Obermaier, El Hombre Primitivo en el País Vasco (1934) de J.M. de Barandiarán o La Préhistoire (1937) de H.Breuil. 
los 40 y 50 aparecen las revistas y series que recogerán novedades e ideas, como Ampurias y Pyrenae en Barcelona, Archivo Español de Arqueología, Excavaciones Arqueológicas en España, Noticiario Arqueológico Hispánico y Bibliotheca Praehistorica Hispana en Madrid, Caesaraugusta en Zaragoza o Zephyrus en Salamanca; mientras que, por entonces, irán también viendo la luz las revistas que acogerán los trabajos de Prehistoria vasca, como Príncipe de Viana desde 1940, Excavaciones en Navarra en 1942, Munibe en 1949, el Boletín de la Institución Sancho el Sabio en 1957, Estudios de Arqueología Alavesa en 1966 o Kobie en 1969. El primer Congreso Arqueológico del Sudeste, de 1945, dará paso, a fines de esa década, a la serie de los Congresos Arqueológicos Nacionales que conduce A. Beltrán e intentarán asegurar un punto de encuentro de las inquietudes y pretensiones de los investigadores; y, con finalidad más específica, a fines de los 50 se empezarán a convocar los Symposia de Prehistoria Peninsular, promovidos por J. Maluquer de Motes.

En un repaso sintetizador del trabajo de campo en esas dos décadas destacaremos: la publicación de los grandes textos de H.Breuil y G.Zbyszewski en 1942-1945 sobre el Paleolítico antiguo portugués, de G.y V.Leisner sobre el megalitismo occidental y meridional y de la memoria de las excavaciones del Parpalló por L.Pericot; las excavaciones en sitios catalanes como las de J.M.Corominas en Serinya (Reclau Viver de 1944 a $1947, \ldots$ ) y las de S.Vilaseca en el Priorato (así la cova del Filador desde 1948); los trabajos de L.Pericot en varios importantes yacimientos levantinos (como Cocina de 1941 a 1945, Mallaetes de 1946 a 1949 o Barranc Blanc de 1951 a 1954); las prospecciones de J.C.Spahni en depósitos musterienses granadinos (como Cueva Horá, Cueva del Puntal y Carigüela en 1954 y 1955) y de J.Waechter en Gorham's Cave (en 1951); la destacada intervención de F.Jordá en la Prehistoria asturiana (excavando, por ejemplo, Bricia en 1953, La Lloseta de 1955 a 1957, El Cierro en 1958) y publicando su esencial revisión del Solutrense peninsular en 1955; o, en Santander, las excavaciones que J.Martínez Santaolalla promueve en El Pendo de 1953 a 1957 y las que llevan a cabo P.Janssens y J.González Echegaray en El Juyo en 1955 y 1956.

La Prehistoria fue asumiendo a lo largo de la década de los 50 varias importantes innovaciones metodólogicas: tales el interés por el mejor control tipológico de las evidencias (en morfología y tecnología), el cuidado en las técnicas de recuperación de los datos (excavación por coordenadas y afinamiento de la percepción estratigráfica) o el deseo por reconocer mejor las circunstancias ambientales en que los yacimientos se formaron. Luego, ya en la 'Prehistoria moderna', se intensificarán el conocimiento de las connotaciones paleoeconómicas, ergológicas o sociológicas de las evidencias, los sitios y las culturas y la preocupación por la situación espacial de los datos (topografía a varias escalas, distribución y funcionalidad,...).

Gestadas esas tendencias innovadoras en otros países, unos $\mathbf{u}$ otros prehistoriadores peninsulares las irán acogiendo, con desigual diligencia, a lo largo de la década de los 60 . Podemos recordar algunas aportaciones de mayor importancia en estos años: como las excavaciones de J.Maluquer de Motes de 1959 a 1964 en la cueva de Berroberría, de E.Ripoll de 1958 a 1964 en cueva Ambrosio, de F.C.Howell de 1961 a 1963 en Torralba y Ambrona, de E.Aguirre en 1963 en Las Gándaras, de M.A.García Guinea y J.González Echegaray en las cuevas de La Chora en 1962 y El Otero en 1963, de L.G.Freeman y J.González Echegaray de 1966 a 1969 en cueva Morín, de M.Almagro y H.T.Irwin de 1966 a 1969 en Cariguiela, las prospecciones y excavaciones de L.Esteva en el megalitismo gerundense o los descubrimientos de sitios tan importantes del arte rupestre paleolítico como las cuevas de Altxerri en 1962, Tito Bustillo en 1968 y Ekain en 1969.

\section{LA SOLVENCIA DE LAS INVESTIGACIONES DE PREHISTORIA DE JOSÉ MIGUEL DE BARANDIARÁN}

Es amplia y sobresaliente la lista de prehistoriadores contemporáneos de J.M.de Barandiarán en los años en que él se incorpora a la investigación de esa especialidad; coetáneos o no suyos, mantuvo con la mayoría 
una relación próxima de intercambio de informaciones según fue progresando en la recopilación de datos y conoció, de todos, sus aportaciones punteras a la Prehistoria de aquellas dos décadas.

Antes de precisar más al detalle el contenido de ese tipo de relaciones profesionales, parece interesante establecer un cuadro de coetaneidad de Barandiarán con algunos de los especialistas de mayor rigor en el estudio del Hombre Primitivo, para fijar la secuencia de generaciones de investigadores en que su actividad se incluye. Así, cuando J.M.de Barandiarán en 1917, cumplidos los 27 años de edad, inicia sus excavaciones, con Aranzadi y Eguren:

- las grandes autoridades de la Prehistoria del momento tienen ya una edad avanzada y fallecerán poco después, como es el caso de los arqueólogos Oscar Montelius (1843-1921) y Emile Cartailhac (18451921), o han pasado sobradamente de la cincuentena, como les ocurre a los antropólogos Telesforo de Aranzadi (1860-1945) y Marcellin Boule (1861-1942), a los paleontólogos y cuaternaristas Alfred Penck (1858-1945) y Henry F. Osborn (1857-1935), a los arqueólogos Salomon Reinach (1858-1932) y Otto Schrader (1855-1919) y a los prehistoriadores Luis Siret (1860-1934), Leon Henri-Martin (1864-1936), Hubert Schmidt (1864-1933) y Henri Bégouën (1863-1956), habiendo muerto poco antes, en los inicios de la primera guerra mundial, el importante sistematizador Joseph Déchelette (1862-1914);

- en otro grupo posterior, que se acerca a los cincuenta años de edad, se hallan el etnólogo Wilhelm Schmidt (1868-1954), los prehistoriadores Denis Peyrony (1869-1954), Georg Leisner (1870-1957) y Conde de la Vega del Sella (1870-1941) y el cuaternarista Eduardo Hernández Pacheco (1872-1965); y hay una generación inmediata después, que acaba de cumplir los cuarenta años y es la inmediatamente precedente a la de Barandiarán, con prehistoriadores de renombre como Jean Bouyssonie (1877-1965), Henri Breuil (1877-1961), Hugo Obermaier (1877-1946), Joan Serra i Vilaró (1879-1969) y Gustav Schwantes (1881-1960) o, más en relación con los yacimientos vascos, el Conde de Saint-Périer (18771950) y Emmanuel Passemard (1876-1945);

- son prácticamente de la edad de J.M.de Barandiarán su compañero de investigaciones Enrique de Eguren (1888-1944), los prehistoriadores Karel Absolon (1887-1960), Raymond Lantier (1886-1978), Raymond Vaufrey (1890-1967) y Nils Äberg (1888-1957), el cuaternarista Wolfgang Soergel (1887-1946), el antropólogo Henri-Victor Vallois (1889-1979) y los arqueólogos Pedro Bosch Gimpera (1891-1974) y Vere Gordon Childe (1892-1957);

- y les sucederán inmediatamente un par de generaciones posteriores: con los que entonces tienen unos diez años menos que J.M.de Barandiarán (o sea, los nacidos por los años 1895-1900) como los prehistoriadores Luis Pericot, Alberto del Castillo, Salvador Vilaseca, Sergei A.Semënov, André Cheynier y Manuel Afonso do Paço, o entre veinte y veinticinco menos (los nacidos entre 1907 y 1915) como los prehistoriadores Hallam L.Movius, Lionel Balout, André Leroi-Gourhan, Jean P.L.Arnal, Martín Almagro y Francisco Jordá, el antropólogo Raymond Riquet y el lingüista Antonio Tovar.

\section{a. Sus relaciones profesionales}

\section{a.l. Sus maestros}

La obra científica de J.M.de Barandiarán sólo es comprensible si se reconocen las dos cualidades más sobresalientes de su personalidad, su curiosidad por el saber y su constancia en el trabajo, que basan y justifican el rigor y puntual conocimiento del estado de las investigaciones de su tiempo. Como tantos eminentes prehistoriadores y etnólogos que empiezan a trabajar en el primer cuarto de este siglo fue un 'autodidacta': la lectura muy cuidadosa de los textos esenciales que entonces iban ordenando las nuevas disciplinas, la asisten- 
cia a series de conferencias o cursos de especialización, la asesoría e informaciones de los más expertos y una racional autocrítica de sistemas de trabajo y posibilidades fueron quienes le aportaron los instrumentos metodológicos y de información que no pudo obtener en cursos académicos oficiales de Prehistoria o Etnología que - por lo demás - aún no se habían empezado a impartir sino en poquísimas Universidades de Europa (y en ninguna de las de España) ${ }^{4}$.

J.M.de Barandiarán ha reconocido insistentemente como personas de especial relación con él y de los que en algún modo se sentía intelectualmente deudor, como 'maestros' suyos, a Wilhelm Wundt y a Telesforo de Aranzadi.

A los cursos del filósofo, sicólogo y antropólogo alemán W.Wundt (1832-1920) del verano de 1913 en la Universidad de Leipzig sobre "Psicología de los Pueblos" asistió el joven Barandiarán, motivándole en la necesidad de mantener siempre una actitud crítica de las ideas y encauzándole en la investigación etnográfica sobre la realidad inmediata de su propio pueblo que desarrollará durante toda su vida. Recién vuelto de aquellos cursos escribirá en su diario, en el mismo año 1913, que "urge la investigación etnográfica del pueblo vasco y la solución, si cabe, de los problemas planteados en ese campo" (L. de Barandiarán 1976: 52).

T. de Aranzadi fue quien encauzó en 1916 sus deseos de trabajar en yacimientos prehistóricos y lo integró, con E.de Eguren, en su equipo de investigaciones. Barandiarán siempre encontró en Aranzadi un asesor expertísimo en Antropología Física y en Etnografía, un meticuloso y cordial cooperador durante cerca de veinte años de campañas de Arqueología de campo y un sabio compañero de provechosos viajes de estudio a colecciones europeas.

El listado de quienes de algún modo ejercieron su influencia por esos años en J.M.de Barandiarán debe ampliarse con los nombres de otros prehistoriadores o etnólogos de quienes recibirá información y aportaciones doctrinales que van afinando su propia obra en cuanto al método de recuperación de datos y a la teoría de su interpretación. Es el caso de Henri Breuil (a cuyos cursos de Prehistoria en el Institut de Paléontologie Humaine de París asistió Barandiarán durante los primeros meses de 1923 y en 1936), Hugo Obermaier, Pedro Bosch Gimpera o el Conde de la Vega del Sella entre los prehistoriadores y de los etnólogos de la Escuela de Viena Wilhelm Schmidt y Michael Haberlandt (del que seguiría el curso que impartió en Viena en el verano de 1929).

\section{a.2. El cruce de su correspondencia de 1915 a 1936}

La revisión de la correspondencia que se ha conservado (doscientas tres cartas recibidas por J.M.de

4. Aparte de las tareas de dirección y asesoría que desempeñó en los más importantes centros y sociedades de estudio de la cultura vasca (director en 1947 de la Sociedad Internacional de Estudios Vascos y presidente, desde 1976, de la Sociedad de Estudios Vascos), J.M. de Barandiarán fue viendo reconocida la importancia de su trabajo científico en un 'curriculum' muy destacado en el que sobresalen su integración en puestos de responsabilidad de institutos superiores de investigación (así fue corresponsal en España (desde 1920) del Instituto Anthropos de Viena, miembro del Consejo Permanente de los Congresos Internacionales de Ciencias Antropológicas y Etnológicas (desde 1935) y de la Comisión Internacional de Artes y Tradiciones Populares de la UNESCO (desde 1938) y chargé de mision del CNRS de Francia (desde 1940)), el encargo de cursos universitarios de especialización (impartió en 1952, por invitación del Rector A.Tovar, el primero de los cursos de la Cátedra "Larramendi" de la Universidad de Salamanca y, entre 1965 y 1977, fue titular de la Cátedra de Lengua y Cultura Vascas de la Universidad de Navarra), la colación de varios Doctorados honoris causa (en 1978 por la Universidad del País Vasco, en 1986 por la Universidad de Deusto, en 1987 por la Universidad Complutense de Madrid) o la obtención de muy altas condecoraciones (como las Medallas de Oro del Gobierno de Navarra, de la Diputación Foral de Alava y la de Bellas Artes en 1990 y la Gran Cruz de la Orden de Carlos III en 1991). 
Barandiarán entre 1915 y 1936: editadas por L.de Barandiarán 1989) centra bien el tema de sus relaciones profesionales con los estudiosos de su tiempo.

Entre los que envían esas cartas a Barandiarán se encuentran, además de sus colaboradores inmediatos Telesforo de Aranzadi y Enrique de Eguren, un conjunto nutrido de especialistas en las disciplinas que cultivó durante esos años. Son prehistoriadores como Hugo Obermaier (del que se conservan siete cartas), Henri Breuil (cuatro cartas), Eduardo Hernández Pacheco, José Pérez de Barradas, Juan Cabré, Pedro Bosch Gimpera y Luis Pericot, etnólogos como Wilhelm Schmidt, Alejandro Guichot, Eduard Hoffmann-Krayer, Robert Aitken y Julio Caro Baroja (que, avanzados los años 30, estaba iniciándose en esos estudios) y naturalistas como Cándido Bolívar, Longinos Navás y Orestes Cendrero. También escriben a Barandiarán los responsables de los museos e instituciones de investigación vascos, autoridades en Arqueología, Historia Local y del Arte, Folklore o Lingüística (como Julián Elorza, Angel de Apraiz, Gregorio Mújica, Federico Baraibar, Carmelo de Echegaray, Bonifacio de Echegaray, Pedro M.de Soraluce, Gregorio Mújica, Juan Allende-Salazar, Justo Gárate, José Aguirre, Luis Larrea, Angel Irigaray, Fausto Arocena,...) ${ }^{5}$.

Esa correspondencia se organiza en tres lotes según su remitente y contenido, es decir su intención y alcances. El primero se refiere a las campañas de investigación y está constituido por las cartas que le envían T.de Aranzadi (cincuenta y ocho) y E.de Eguren (diecinueve) y contienen, obviamente, informaciones bastante extensas y comentarios detallados sobre el proceso de las investigaciones y su metodología. El segundo recoge "las primeras reacciones ante los descubrimientos científicos", destacando las que le dirigen quienes, como H.Breuil, J.Cabré, H.Obermaier o P.Bosch Gimpera, desarrollan en ese tiempo investigaciones muy importantes en la Prehistoria peninsular. El tercer lote está integrado por las cartas que acusan recibo de textos o datos o los solicitan.

Henri Breuil es siempre aludido en las publicaciones de Barandiarán con respeto y tomadas con cuidado sus reflexiones científicas. El propio Aranzadi hace alusión en varias cartas que envía a Barandiarán a observaciones que le ha hecho llegar Breuil (por ejemplo, sobre la conveniencia de incluir planos más precisos de los dólmenes excavados y detallar bien sus escalas) y a la necesidad de asumirlas. El discurso que Barandiarán pronunció en la apertura del Curso del Seminario de Vitoria sobre las investigaciones prehistóricas en el País Vasco causó una excelente impresión en Breuil, quien le envía el 6 de octubre de 1917 una extensa carta (L. de Barandiarán 1989: 101), animándole a afrontar un estudio sistemático de esos temas y a ponerse en relación con H. Obermaier.

De Hugo Obermaier recibió algunas cartas de compromiso y otras francamente cordiales; Barandiarán conoce a fondo los textos de Prehistoria de Obermaier y los cita en sus publicaciones con admiración. El conocimiento y trato entre ambos fue bastante inmediato, a partir de algún tema de común dedicación (como el estudio de las cuevas artificiales alavesas) y de la amistad compartida con Luis Heintz, Constantino Díez, Pedro Ruiz de Azúa y otros profesores de los colegios de Santa María (de Vitoria) y del Pilar (de Madrid), que intervinieron activamente en prospecciones y excavaciones arqueológicas de J.M.de Barandiarán, E.de Eguren y H.Obermaier. Reiteradamente J.Caro Baroja (estudiante por los años 1932 a 1935 en la Universidad Central

5. Por otra parte, los remitentes de cartas a J.M.de Barandiarán en el período 1952 a 1991 (L.de Barandiarán 1995 publica una selección de doscientas ochenta y una cartas) constituyen un muy amplio listado de conocidos especialistas de estas últimas décadas como los prehistoriadores J.Martínez Santaolalla, M.Almagro Basch, L.Méroc, H.Kühn, M.Sarradet, A.del Castillo, H.L. Movius, C.Alonso del Real, A. Leroi-Gourhan, D.de Sonneville-Bordes, A.Glory, A.Beltrán, G.Laplace, J.Maluquer de Motes, E.Sangmeister, A.Laming-Emperaire, B.Blance, E.Vallespí, A.Muñoz Amilibia, A.Llanos, J.Altuna, J.M.Apellániz, I.Barandiarán, T.Andrés, A.Baldeón, L.G. Straus, M.A.Beguiristain y C.Chauchat, los paleantropólogos R.Riquet, K.P.Oakley, J.M.Basabe y P.Marquer o el cuaternarista C.Thibault. 
y alumno de Obermaier) en sus cartas a J.M.de Barandiarán incluye alguna postdata muy significativa ("don Hugo Obermaier me encarga le salude de su parte siempre que le escriba").

También fueron excelentes las relaciones de Barandiarán con Pedro Bosch Gimpera. Motivadas por el común interés por el conocimiento de los pueblos pirenaicos al que los trabajos de Aranzadi, Barandiarán y Eguren aportaban muchos datos de excepcional importancia; $y$, desde luego, por la estima que ambos tienen por el trabajo y conocimientos de T.de Aranzadi que, como Bosch, era Catedrático en la misma Universidad de Barcelona y al que el prehistoriador catalán dedicó en 1923 su ensayo sobre el problema etnológico vasco y la Arqueología. Alguna importante obra de síntesis de Bosch Gimpera será objeto de reseña detenida y muy elogiosa de Barandiarán y en varias ocasiones intervenieron juntos en ciclos de lecciones de su especialidad ante diversos foros.

Sin que en su correspondencia pasiva haya motivos para asegurarlo, sospechamos, por otros indicios, que Barandiarán mantuvo relaciones científicas de interés con el prehistoriador Conde de la Vega del Sella (así lo afirma éste en sus diarios, a propósito, por ejemplo, del estudio de los niveles mesolíticos de Santimamiñe: Márquez 1974a: 122 y en información oral), con el antropólogo Luis Hoyos (que tenía buena amistad con T.de Aranzadi) y con otros arqueólogos.

Con su habitual estilo directo T.de Aranzadi, en su correspondencia a Barandiarán, califica a algunos de esos colegas: habla a menudo y bien, con respeto, de H.Breuil y de H.Obermaier (p.e., asegura de éste, en carta del 2 de julio de 1919, que "es muy comedido"), estima las opiniones de P.Bosch Gimpera y se muestra reticente con J.Cabré ("no nos fiemos de Cabré" advierte a Barandiarán en esa misma carta, a propósito de las ideas del arqueólogo aragonés sobre las cuevas artificiales del sur de Alava).

\section{a.3. Sus relaciones profesionales}

La obra que Barandiarán publica en esos años, normalmente memorias de excavación firmadas en colaboración con Aranzadi y Eguren y también textos de síntesis producidos exclusivamente por él, fue acogida inmediatamente en las publicaciones especializadas, que se sirven de sus datos o asumen sus interpretaciones.

Muy poco después de la publicación de la correspondiente memoria, el sueco Nils Äberg cataloga ya en su monografía sobre el Eneolítico de la Península Ibérica el vaso campaniforme que Aranzadi, Barandiarán y Eguren habían hallado en 1918 en el dolmen de Pagobakoitza (Äberg 1921: 157). Del mismo modo, los ejemplares estudios de Luis Pericot y Alberto del Castillo sobre la cultura dolménica pirenaica (Pericot 1923/ 1950: 179-180, 196-200) y sobre el vaso campaniforme en Europa (Castillo 1928: 95-96) y el texto magistral de El Hombre Fósil de Hugo Obermaier, en su segunda edición, se hacen eco puntual de esos hallazgos, en curso (así Obermaier 1925: 171: "Cuevas de Ermitya... cuya exploración fué empezada en 1924 por T. de Aranzadi y J. de Barandiarán...", "Cueva de Santimamiñe... explorada desde 1918 por T.de Aranzadi, J. de Barandiarán y E. de Eguren. Las excavaciones no han terminado aún...", haciéndose sendas glosas, bastante amplias, de su contenido arqueológico). Por su parte, la sugestiva y documentada síntesis de Pedro Bosch Gimpera sobre el problema etnológico vasco y la Arqueología contiene reiteradas alusiones a materiales e ideas publicados por J.M. de Barandiarán (Bosch Gimpera 1923: 594, 604, 612,...).

\section{b. Sus informaciones sobre los materiales y datos de comparación}

\section{b.1. Visitas a museos y colecciones}

Sus diarios de aquellos años (cuidadosamente consultados y extractados por L.de Barandiarán 1976: caps.IX 
y XII) refieren puntualmente sus viajes de estudio a las más importantes colecciones e instituciones europeas. Aprovechando los veranos y habitualmente en compañía de T.de Aranzadi, adquiere Barandiarán un conocimiento inmediato de los materiales arqueológicos y etnográficos de mayor interés, los que sirvieron de fundamento a muchas clasificaciones de base y cuya referencia le servirá para el diagnóstico cultural de los datos recuperados en sus propias campañas en el País Vasco. Más aún, la ocasión de la visita fue aprovechada para la consulta de los fondos bibliográficos y el intercambio de informaciones con los responsables de esas instituciones de investigación, que conocen ya el trabajo científico de J.M. de Barandiarán o con quienes se establecen relaciones de correspondencia.

En la crónica de sus viajes señala él mismo el interés concreto suscitado por las colecciones estudiadas de los principales museos y servicios occidentales: entre otros los del Musée du Louvre, Musée d'Ethnographie du Trocadero y depósitos del Institut de Paleóntologie Humaine de París, del Musée des Antiquités Nationales de Saint-Germain-en-Laye, del Museo Arqueológico de Barcelona, del Museo Grassi de Leipzig, de los Bayerisches Nationalmuseum, Deutsches Museum y Museum für Völkerkunde de Munich, de los Museum für Völkerkunde, Alter Museum y Sammlung für Deutsche Volkskunde de Berlín, del Rautenstrauch Joest Museum de Colonia, del Musée d'Histoire Naturelle de Bruselas, del Schweizerisches Landesmuseum de Zürich, del Historisches Museum de Berna o de los Museum für Volkskunde y Naturhistorisches Museum de Viena. Fueron especialmente cuidadas las estancias de estudio estivales de los años 1922 y 1929.

\section{b.2. Conocimientos de bibliografía}

La preocupación por asentar sus intuiciones requirieron de Barandiarán la búsqueda de referencias de comparación para las evidencias que iba descubriendo. Aunque no recargue sus textos con un aparato denso de notas, se puede asegurar que dominaba bien las opiniones y materiales que apoyan sus identificaciones arqueológicas.

Hemos conocido (a partir de 1964) su biblioteca particular de San Gregorio de Ataun (Guipúzcoa), consultando alguno de los textos que ahí conservaba. En ella se contenían los textos básicos de las tres primeras décadas del siglo sobre la Prehistoria occidental, un importante lote de revistas especializadas y una amplia representación de monografías y separatas enviadas por sus autores con aportaciones de la segunda mitad de este siglo.

Lamentamos no haber podido reconstituir los fondos bibliográficos a los que J.M.de Barandiarán tendría acceso en aquellos años 1915-1936 en el Seminario Conciliar de Vitoria; también debió acudir en aquella época a las otras bibliotecas próximas (de Vitoria mismo, o de Bilbao y San Sebastián: de las diputaciones provinciales y de los museos correspondientes, de la Sociedad de Estudios Vascos, etc.): sus fondos, muy completos en bibliografía regional, adolecerían, sin duda, de textos y revistas de alcance más amplio o de orientación muy especializada en Prehistoria. En los años 1965 a 1977 en que profesó en la Cátedra de Lengua y Cultura Vasca de la Universidad de Navarra consultó asiduamente los bien dotados fondos de Prehistoria de esa Biblioteca.

La cita bibliográfica o de documentación gráfica no es, en la obra de Barandiarán, el recurso que en muchos otros autores suele servir, con frecuente exceso, para arropar o dar más apariencia a un texto o aumentar el peso y convicción de los propios argumentos. En las publicaciones de Barandiarán, como en las de Aranzadi, se ofrecen con estimable austeridad la entidad suficiente de los datos propios y las interpretaciones que razonablemente suscitan, ahorrándose toda referencia ajena que no sea estrictamente necesaria.

En las memorias de sus trabajos de campo casi nunca se acude a otro autor para reforzar los diagnósticos propios salvo si ello resulta imprescindible. Cuando, por ejemplo, se publica el estudio del arte rupestre de 
Santimamiñe (Aranzadi, Barandiarán y Eguren 1925: 49) la única referencia requerida para ajustar con cuidado la valoración cronológica de las pinturas es la de la autoridad de H.Breuil, tras discutir si no haya en ellas algo referible al Magdaleniense superior ("por su temática y estilo ... en el arte rupestre cantábrico... quedan, por tanto, como probables las fases magdaleniense inferior y medio, si seguimos la clasificación de H. Breuil").

He listado las referencias de autoridad (notas al pie de página, citas de opiniones ajenas o alusiones a materiales de comparación) en una de sus primeras presentaciones de conjunto sobre la Prehistoria (el cursillo que impartió en 1918) y en sus tres obras de síntesis de mayor entidad en esos años: la Breve Historia del Hombre Primitivo de 1931, los Apuntes de Geología general y de la del País Vasco de 1932 (excelentes manuales de iniciación respectivamente a la Arqueología y Etnología y a la Geología) y El Hombre Primitivo en el País Vasco de 1934 (la primera presentación sistemática de la Prehistoria vasca). Ese lote de referencias nos permite saber qué textos Barandiarán entonces habitualmente manejaba y los autores cuyas opiniones o datos consideraba de primera utilidad.

Sus dos lecciones sobre Prehistoria en el Congreso de Estudios Vascos de Oñate, en 1918, incluyen un listado de referencias que ilustran significativamente sobre el grado de actualidad de la bibliografía que Barandiarán ya entonces conoce y aprecia. Reconoce explícitamente (J.M. de Barandiarán 1919: 362-363) como "fundamentales" las "obras de los sabios Obermaier (sobre todo su hermosa memoria "El Hombre fósil"), Breuil, Dechelette y el "Manuel de Recherches Préhistoriques" de la Sociedad Prehistórica Francesa, en cuyas enseñanzas me he inspirado principalmente al desarrollar el plan de este cursillo". Cuya cita de autoridades (que aluden, obviamente a la primera edición, de 1916, de El Hombre Fósil de H.Obermaier, al fundamental esquema Les subdivisions du Paléolithique Supérieur et leur signification de 1912 de H.Breuil, al exhaustivo Manuel d' Archéologie préhistorique, celtique et gallo-romaine de 1908-1913 de J.Déchelette y al Manuel de Recherches Préhistoriques de la Sociedad Prehistórica Francesa de 1906) se completa con las que se refieren en otros lugares de ese cursillo como la cuidadosa Nomenclatura de voces técnicas y de instrumentos típicos del Paleolítico que editó en 1916 la Comisión de Investigaciones Paleontológicas y Prehistóricas (en cuya redacción intervinieron E.Hernández Pacheco, H. Obermaier, P.Wernert y el Conde de la Vega del Sella, siendo la mayoría de los dibujos de J.Cabré), varios textos de J.Cabré sobre arte de la Prehistoria avanzada, la imprescindible Les âges préhistoriques de l'Espagne et du Portugal de 1886 de E.Cartailhac y, desde luego, la práctica totalidad de los textos entonces disponibles sobre la Prehistoria vasca.

La Breve Historia del Hombre Primitivo (J.M. de Barandiarán 1931) tiene una finalidad didáctica expresa en su dedicatoria, como manual de introducción destinado "a los jóvenes colaboradores del Laboratorio de Etnología y de Eusko-Folklore que, a fin de iniciarse en el estudio de la historia primitiva del hombre, han manifestado reiteradamente deseos de conocer los resultados y los métodos de investigación y de interpretación usuales en la Arqueología prehistórica y en la Etnología".

Su primera parte, que trata de "El Hombre Primitivo según los datos arqueológicos", consta de un texto de noventa y ocho páginas que incluyen un repertorio de cincuenta y nueve figuras. Para ilustrar los materiales vascos en el contexto de la Prehistoria occidental se acogen en la obra figuras de Mas d'Azil, Castillo, Almadén, Saint-Marcel, Le Placard, del arte levantino y esquemático español y Laugerie-Basse (en la fig.1: tomadas de publicaciones de E. Piette, J. Déchelette, H. Breuil, H. Obermaier y J. Cabré), la mandíbula y estratigrafía de Mauer (figs. 6 y 7), bifaces de San Isidro y Torralba (figs. 9 y 10), un cráneo de la Chapelleaux-Saints (fig. 15), puntas musterienses de La Quina (fig. 18), materiales varios de Cueto de la Mina (figs. 25 y 26), La Grèze (fig. 27), Chancelade (fig. 29), Combarelles, Arudy, Gourdan, Altamira y Font-de-Gaume (figs. 30, 31 y 32: tomadas de recopilaciones de H. Breuil y S. Reinach), Peña Tu y Los Millares (fig. 46), Locmariaquer, Morbihan y Gavr'inis (fig. 67), ... con un amplio repertorio iconográfico para las Edades del Bronce y del Hierro (que se asume básicamente del corpus de J. Déchelette y se completa con los de algunos especialistas alemanes). 
Los cuatro corpora iconográficos empleados reiteradamente en este sustancioso manual de Prehistoria de J.M.de Barandiarán son obras de tanta enjundia en el contexto de la bibliografía contemporánea como el tan usado en ese tiempo Musée Préhistorique de Gabriel y Adan de Mortillet, en la edición segunda de 1903 (que es utilizado por Barandiarán en las pp. 59, 62,... de su Breve Historia del Hombre Primitivo), el útil Répertoire de l'Art Quaternaire de Salomon Reinach de 1913 (del que se toman unas cuantas ilustraciones), el tan completo en texto e ilustraciones Manuel d'Archéologie préhistorique, celtique et gallo-romaine de Joseph Déchelette de 1908-1913 (que se cita por Barandiarán reiteradamente; así en pp. 57, 58, 59, 62, 72, 82, 86, 89, 95, 97,...) y, obviamente, el magistral El Hombre Fósil de Hugo Obermaier en su segunda edición de 1925.

Entre las autoridades aludidas en el texto o en las correspondientes notas bibliográficas del libro de J.M. de Barandiarán de 1931 sobre el Hombre Primitivo están los más prestigiosos expertos en climatología y medio del Cuaternario (en pp.13,17,...) como A.Penck y E.Brückner, W.Soergel, G.de Geer para lo nórdico, A.L.Wegener, W.Köppen y H.Obermaier. Del mismo modo, se emplean los mejores textos entonces al día sobre las culturas del Paleolítico: con reiteradas alusiones a H.Breuil ("el sabio abate Breuil" en p.33; citando su fundamental Les subdivisions du Paléolithique Supérieur et leur signification del Congreso de Ginebra de 1912, en p.34; etc.) y, sobre todo, a H.Obermaier (del que concretamente se consignan la segunda edición de El Hombre Fósil de 1925, en p.34, La vida de nuestros antepasados cuaternarios en Europa de 1926, en p. 48, y El hombre prehistórico y los orígenes de la humanidad de 1932, en p. 78) y precisiones de la importante contribución del Man of the Old Stone Age de H.F.Osborn (a partir de su tercera edición, en p.18), del Nordische Paläolithikum und Mesolithikum de G.Schwantes de 1928 y de los trabajos de S.Sergi $(1918,1929, \ldots)$ sobre antropología de los neandertales. Para la Prehistoria holocena Barandiarán reconoce el apoyo de las aportaciones del Conde de Gerin en lo referente al Epipaleolítico (pp. 53 y 54), de E.Cartailhac para el megalitismo bretón (p. 67), de H.Schmidt para la cultura de El Argar (p. 72) y, para la metalurgia del Calcolítico al Hierro con todos los aspectos implicados sobre lo "ario" e "indogermano" en cultura material e ideas, a los autorizados O.Schrader del Die Indogermanen de 1919 (p. 70), L.von Schroeder de Arische Religion de 1923 (p. 75) y A.Carnoy de Culture et religion des Indo-Européens de 1923 (p. 77), y al volumen II del Manuel d'Archéologie préhistorique, celtique et gallo-romaine en edición de 1913 de J. Déchelette (según apuntábamos anteriormente).

En su manual de Geología (J.M. de Barandiarán 1932), de ciento veintiseis páginas de texto, se incluye un amplio lote de ilustraciones (ciento cuatro) en dibujo y fotografías. La casi totalidad de las fotografías que ilustran la Geología vasca, y unas cuantas de las referidas a fenómenos glaciares centroeuropeos, han sido hechas por J.M.de Barandiarán. El resto de las ilustraciones es asumido o inspirado de tratados excelentes de la Geología del primer cuarto del siglo, sean obras de conjunto o monografías particulares, como las tan conocidos en España del minerálogo P.Ferrando Mas y del geólogo M. San Miguel de la Cámara, del físico J.H. Jeans o de los especialistas J. Gaberell, J. Mazo, M. Terán, etc. En cuanto a las referencias del texto de Barandiarán a autoridades, esos apuntes de Geología acogen opiniones de algunos especialistas ya clásicos como las referidas a geogenia de P.S. Laplace o las del biólogo A.Herzen junto a las novedades más recientes del climatólogo A.L. Wegener, de los geólogos H. Haas (en su denso Leitfaden der Geologie de 1920) y J.J. Landerer (autor de los provechosos Principios de Geología y Paleontología, en edición castellana de Barcelona, de 1917 a 1919) y, muy en particular, de los especialistas en geomorfología del paisaje vasco R. Adán de Yarza, J. Scheu, F. Marquina, J.M. Susaeta, V. Kindelán y P. de Aranegui.

El Hombre Primitivo en el País Vasco (J.M. de Barandiarán 1934) es una obra ceñida al ámbito espacial al que se han referido inmediatamente las importantes investigaciones de Barandiarán, aportando un caudal sustancial de datos y del que él poseía, por tanto, un conocimiento directo y muy completo. Es así como, en lógica, no se requiere del recurso a apoyaturas ajenas de documentación o aserto. Sus citas a obras de otros investigadores se reducen a cinco referencias que, de todos modos, nos informan puntualmente sobre las 
autoridades que gozan de su aprecio: se trata de M.Boule en Les Hommes Fossiles. Elements de Paléontologie Humaine por su segunda edición de 1923 (citado en p.19), de "el ilustre arqueólogo Bosch Gimpera" (en su obra Los pueblos primitivos de España que publicó la Revista de Occidente en 1925) (citado en p.24), de "el sabio profesor Obermaier" en El hombre prehistórico y los orígenes de la humanidad de 1932 (en p.50), de "las interesantes investigaciones de O.Schrader" en Die Indogermanen de 1919 (en p.81) y de las novedades recopiladas por J.Altadill en Vías y vestigios romanos en Navarra de 1928 (en p.103).

\section{EVALUACIÓN DE LA OBRA DE J.M.DE BARANDIARÁN EN EL CONTEXTO DE LA PREHISTORIA CONTEMPORÁNEA}

En la historia de las investigaciones prehistóricas en el País Vasco se reconoce, tras una fase de iniciación de los estudios, una etapa de consolidación de los trabajos, que ocupa la segunda y tercera décadas del siglo. Se caracteriza esta etapa por la intensificación del conocimiento del fenómeno dolménico y de la ocupación de cuevas en el Paleolítico superior y, en general, por la sensible ampliación del catálogo de yacimientos a diversas zonas del territorio. Ahí es indiscutible el protagonismo de la dedicación por entonces de Barandiarán que, solo o en equipo con Aranzadi y Eguren, incorpora el resultado de múltiples prospecciones al programa de excavaciones más intensas desarrollado en determinados yacimientos de mayor importancia y al estudio más general de las culturas que en el tiempo prehistórico se asentaron en estas tierras del Pirineo occidental y de la alta cuenca del Ebro.

Más concretamente hemos destacado (I.Barandiarán 1988: 71-76) tres tipos de valores especiales en estos veinte años, de 1917 a 1936, de trabajos arqueológicos: la idoneidad de la metodología de excavación y estudio, el abrumador incremento de datos que se aportan y el esfuerzo que hubieron de realizar Barandiarán y sus compañeros para llevar adelante empresa tan ambiciosa.

Destacan, en primer lugar, la modernidad y eficiencia de la metodología puesta en juego en las excavaciones y la precisión de los juicios y evaluaciones que se publicaron. Llama en especial la atención el carácter pluridisciplinar de las memorias de excavación, recogiéndose en ellas diversas perspectivas complementarias de lo estrictamente arqueológico: como la consideración del paisaje actual en fauna y flora y climatología, la etnografía, la determinación de las especies prehistóricas y un cuidado análisis de los restos antropológicos recuperados.

En segundo lugar, se reconoce como impresionante el número y calidad de los datos con que las excavaciones de aquel equipo de trabajo y las revisiones de conjunto de J.M.de Barandiarán contribuyen al repertorio de informaciones sobre la Prehistoria vasca. Las secciones correspondientes de los museos provinciales adquieren de hecho, en esos años, su entidad real: bien porque se amplían sustancialmente los modestísimos fondos de Prehistoria de que hasta entonces disponían (es el caso, por ejemplo, del Museo Municipal de San Sebastián, o de las colecciones del "Museo incipiente" vitoriano o del Museo de la Cámara de Comptos de Pamplona) o porque se crean de nuevo esas instituciones de custodia patrimonial (como sucede con el Museo Arqueológico de Vizcaya y Etnográfico Vasco de Bilbao que se constituye en 1921 o el Musée Basque de Bayona en 1922, que se benefician inmediatamente de los restos que van recuperándose en las excavaciones en curso). Del mismo modo se da entonces la aparición de algunas revistas directamente relacionadas con esos contenidos de Antropología Cultural (el "Anuario de Eusko-Folklore" en 1921 y el "Bulletin du Musée Basque de Bayonne" en 1924) en que algunas de las investigaciones prehistóricas de ese tiempo serán acogidas.

En tercer lugar, hay que admitir el esfuerzo de aquel trabajo de investigación, teniendo que compaginar sus habituales compromisos académicos (siendo catedráticos Aranzadi y Eguren de las Universidades de Barcelona y Oviedo, y Barandiarán del Seminario Conciliar de Vitoria) con expediciones de prospección y excavaciones en los meses del verano, disponiendo de presupuestos no excesivos y chocando, en bastantes 
ocasiones, con las reticencias o con la oposición de diversos medios sociales (la de la erudición establecida, p.e., o en el caso de Barandiarán la de alguno de sus superiores eclesiásticos, según se detalla en su biografía por L.de Barandiarán 1976) ${ }^{6}$.

Concluido su exilio en 1953, J.M.de Barandiarán será quien reactive con energía toda la investigación prehistórica en Guipúzcoa, Alava y Vizcaya protagonizando, como director, las excavaciones de estas provincias durante cerca de veinte años. Entonces se constituye en el impulsor de una real 'escuela', a través de quienes, estudiantes de especialidad en varias universidades en los años del paso de la década de los 50 a los 60 , se incorporan a la colaboración en sus trabajos de campo: ellos irán constituyendo a su vez los grupos que empezarán a hacerse cargo a fines de los 60 de la dirección de las excavaciones y de la coordinación de las más recientes generaciones de estudiosos.

Las excavaciones y publicaciones de la segunda época de las investigaciones de J.M.de Barandiarán ofrecen, en el contexto del panorama de la Prehistoria peninsular de mediados los 50 a inicios de los 70, una seria garantía de precisión en el método de recuperación de los datos y de rigor en su interpretación.

\section{a. El sentido de sus investigaciones}

En 1991, pocos meses antes de morir, J.M. de Barandiarán reflexionaba en público sobre la orientación general de sus investigaciones sobre lo primitivo o tradicional en el País Vasco: "lo básico de nuestro designio es el método de rebusca de hechos, el trabajo sobre el terreno, el conocimiento del entorno al que nos hallamos estrechamente ligados. Esta ha sido nuestra andadura etnográfica desde sus comienzos". Hace pocos meses en un acto público en que se analizaba la obra científica de J.M. de Barandiarán la calificó el etnólogo J.M.Satrústegui de positivista y con esquemas cartesianos; y reconocía la importancia de los paralelismos que en su día Barandiarán estableció por cuanto que se apoyan en la captación de materiales de primera mano cuyo valor, pasando el tiempo, no ha sido desautorizado.

Cuando en 1916 Barandiarán se empezó a dedicar al estudio del hombre primitivo, el panorama general del estado de los conocimientos ofrecía, como antes recordábamos, un nivel medianamente aceptable de los referentes a la Prehistoria del occidente de Europa (así las culturas del Paleolítico aquitano y cantábrico o el megalitismo bretón), que empezaba a alcanzar su madurez, y una gran necesidad por colmar la investigación etnográfica de las viejas etnias. De ese modo su primera presentación de síntesis (J.M.de Barandiarán 1917) es a la vez un claro programa de objetivos e intenciones, al que habrá de dedicar su posterior dilatada actividad

6. El mismo J.M.de Barandiarán (1951) rememoraba, al hacer balance de sus investigaciones con T.de Aranzadi, la dureza material del trabajo de campo de aquellos años: "La labor inherente de una campaña de exploración, siquiera fuera ésta de quince días, resultaba siempre harto penosa. Piénsese en aquellos recorridos diarios, a pie y por parajes difíciles: de Erremedio a Arraztaran y a Uelogüena (primera campaña de Aralar); de Enirio a Igaratza y a Unaga (segunda campaña de Aralar); de Aranzazu a Urbía (campaña de Aitzkorri); de Kaseta a Intxusburu (campaña de Atáun-Borunda); de Ursuaran a Balenkaleku y a Otzaurte (campaña de Altzania); de Elosua a Irukutzeta y a Atxolin (campaña de Elosua-Plazentzia); del Palacio de Urbasa a Artekosaro (campaña de Urbasa); de Burguete a Atalosti y a Lindus (campaña de Auritz y Aurizperri), etc... A las dificultades de desplazamiento se añadía el trabajo, generalmente ingrato, de la exploración y las incomodidades del lugar ... Setecientas cincuenta pesetas nos dió la Diputación de Guipúzcoa en el primer año, y mil en los siguientes. Casi todo lo que conocemos hoy del pasado prehistórico de esta región, obra de nuestro esfuerzo de veinte años, no costó a las arcas de su Diputación veinte mil pesetas. Algo más nos pagaba la Diputación de Vizcaya, lo que permitía que duraran más tiempo nuestras exploraciones en aquella región. Con todo, los gastos ocasionados por tales trabajos sobrepujaban en mucho a los créditos acordados por las Diputaciones y requerían siempre el concurso de nuestro peculio particular". 
de investigador: consiguiendo, primero, el mínimo de datos necesarios (mediante excavaciones) y ofreciendo, luego, una visión coherente de la Prehistoria vasca en su contexto europeo-occidental.

La dedicación a la Prehistoria por el equipo de Barandiarán en las dos décadas inmediatas aporta un catálogo muy apretado de campañas estivales de excavación que se suceden sin interrupción, destacando las exploraciones dolménicas en los grupos del Aralar (1917), Aitzgorri (1918), Ataun-Borunda (1919), Entzia (1920), Altzania (1920), Urbasa (1921) y Elosua-Placencia (1921) y las excavaciones de los niveles de ocupación de las cuevas de Santimamiñe y Lumentxa (entre 1918 y 1926), Ermittia (de 1924 a 1926), Urtiaga (de 1928 a 1936) y Bolinkoba (en 1932 y 1933); además de decenas de identificaciones de nuevos yacimientos, en cuevas, megalíticos o al aire libre, que Barandiarán aportó en sus prospecciones de campo.

En el equipo de investigadores que trabajó en estas tierras antes de 1936 se daba una efectiva distribución de responsabilidades bajo la dirección de Aranzadi, al que Barandiarán y Eguren reconocen como maestro por la obvia importancia de sus aportaciones etnográficas y antropológicas y por la diferencia de los treinta años de edad que les lleva. En las memorias de excavación de aquellos años se percibe ese reparto de responsabilidades en los trabajos de campo: Aranzadi se encarga, al principio, de la redacción de los diarios y se responsabiliza de la recogida y control de los restos humanos y animales, Barandiarán asume el inventario y estudio del material arqueológico y Eguren el del conjunto de los aspectos relacionados con las Ciencias Naturales, aportando todos sus reflexiones sobre Etnografía y paralelos.

Del mismo modo, cuando se trata de repartirse los temas a desarrollar en alguna reunión científica a la que los tres asisten es habitual que sea Barandiarán el encargado de desarrollar los temas de Prehistoria, por reconocerle sus colaboradores como al más capacitado en esas cuestiones; y eso sucede a lo largo de los veinte años de su cooperación científica. Así, por ejemplo, cuando en el Primer Congreso de Estudios Vascos, en Oñate en 1918 (véanse sus Actas publicadas al año siguiente), dentro de la sección de Raza se encargan sendos cursillos de dos lecciones cada uno: sobre Etnografía a T.de Aranzadi, sobre Antropología a E. de Eguren y sobre Prehistoria a J.M. de Barandiarán. O, más específicamente, cuando en diciembre de 1934 la Junta de Cultura Vasca de Bilbao organiza un Curso de Prehistoria bajo la dirección de T. de Aranzadi, quien distribuye las lecciones entre E. de Eguren, H. Obermaier, P. Bosch Gimpera, J. Cabré, J.M. de Barandiarán y él mismo, encargando a Barandiarán de los temas nodales de esta Ciencia. Así se dirige Aranzadi a Barandiarán (en cartas de los días 7 y 17 de noviembre de 1934), reservando dos lecciones sobre cerámica a Bosch Gimpera y encargando a Barandiarán otras dos: "podría tratar en una (o parte de ella) de tipología de los pedernales (o si es caso de huesos o cuernos trabajados)" además de "estratigrafía y cronología".

Para conocer el pasado y evolución de las culturas del País Vasco se ha servido la obra científica de Barandiarán de una doble vía de percepción complementaria, prehistórica y etnográfica. Varias ideas fundamentales parecen subyacer a esa investigación paralela facilitando argumentos en favor de la articulación de sus datos respectivos en una explicación aparentemente coherente de las evidencias que, por vía de excavación o de encuesta, se iban recuperando.

En los textos que J.M. de Barandiarán escribió en los años 20 a 40 se insiste en la idea de que en la historia del pueblo vasco se ha producido algún tipo de continuidad entre lo prehistórico y lo tradicional; participan así, como señalábamos anteriormente, de una corriente de pensamiento históricocultural profundamente arraigada en la Prehistoria del primer tercio del siglo. Esa idea de concatenación se refiere a tres aspectos: la antropología física, argumentando a favor de la pervivencia del tipo humano desde el del Paleolítico superior al actual pirenaicooccidental (apoyándose en las definiciones antropométricas establecidas por T.de Aranzadi en los años 10 y 20 y en la aparente evidencia estratigráfica de la secuencia de la cueva de Urtiaga, que se excava en la primera mitad de los 30); determinados elementos de cultura material o simbólica (así la continuidad de los modos de vida pastoril de lo dolménico hasta ahora o la simbología del arte rupestre que para Barandiarán encarna aún en mitos de la tradición oral de los vascoparlantes); y la propia lengua, que se estaría 
gestando en la Prehistoria avanzada. Pero hay que reconocer que la relativa rotundidad de los argumentos (o, al menos, de la formalización de su enunciado) con que se exponen esas interpretaciones en algunos textos de Barandiarán de aquellos años (por ejemplo los aportados en 1932 al "Anuario de Eusko-Folklore", en 1935 al homenaje a E. de Escarzaga y en 1941 a la revista "Paideuma") se atenúa, hasta incluso desaparecer en sus publicaciones posteriores, a causa de la reflexión crítica que suscitan la complejidad y mayor número de evidencias que se iban reuniendo con el paso del tiempo y por su contraste con el contexto teórico de nuevas tendencias y opiniones.

Al denso balance de excavaciones de aquellos años 1917 a 1936 se añade, tras sus años de exilio, el nutrido efectivo de estratigrafías, materiales e interpretaciones producido por los trabajos que dirigirá en la segunda mitad de los años 50 y a lo largo de los 60 . Se trata, entre otras, de las excavaciones y estudio de yacimientos tan importantes como los de las cuevas de Lezetxiki (entre 1956 y 1968), Atxeta (en 1959 y 1960), Aitzbitarte IV (de 1960 a 1964), Marizulo (de 1962 a 1967), Ekain (entre 1969 y 1972) y los abrigos del Montico de Charratu (en 1965 y 1966) y Axlor (entre 1967 y 1974), los depósitos de Kurtzia (1959), los conjuntos rupestres de Altxerri (1962) y Ekain (1969), los dólmenes riojanos (en 1963 y 1964) o el castro de Intxur (de 1957 a 1959) y, reiterando nuevas campañas en los yacimientos, que había empezado a excavar antes de la guerra civil, en las cuevas de Urtiaga (en 1954, 1955 y 1959), Santimamiñe (de 1960 a 1962) y Lumentxa (en 1963 y 1964).

\section{b. El método de recuperación de los datos en excavación}

\section{b.1. En la etapa 1917 a 1936}

En el período 1917 a 1936 en el que Aranzadi, Barandiarán y Eguren (a partir de 1922 trabajarán solos Aranzadi y Barandiarán, por enfermedad crónica de Eguren) desarrollan su densa actividad de Arqueología de campo, la Prehistoria occidental experimenta una notable depuración de los sistemas de recogida de datos, en lo referente a cartografía, a identificación y levantamiento de los niveles y a recuperación de los restos.

Es en ese tiempo cuando se asimilan y ponen en práctica las recomendaciones y conocimientos aportados por los primeros tratados metodológicos propios, como el manual de investigaciones de campo que pocos años antes (en 1906) había editado la Sociedad Prehistórica Francesa o la nomenclatura de identificación tipológica de la Comisión de Investigaciones Paleontológicas y Prehistóricas (en 1916): son textos que Barandiarán conoce y cita con encomio, igual que las obras básicas de G. y A.de Mortillet (en edición de 1903), de J.Déchelette (de 1908 a 1913), etc., que antes recordábamos. En esa época es común la preocupación de quienes están emprendiendo excavaciones por afinar sus métodos de recuperación: así, por referir un ejemplo próximo, recordaríamos las prolijas anotaciones que el Conde de la Vega del Sella dejó en sus cuadernos manuscritos de 1915-1916 sobre las condiciones de una excavación correcta (bajo epígrafes en que se desarrollan temas tan concretos como "Manual", "El excavador y los obreros", "La mezcla en los yacimientos", etc.: véase Márquez 1974b: 812-818).

J.M. de Barandiarán, siempre parco en sus expresiones, no ha hecho alusión directamente ni en forma extensa a la teoría y práctica del método de recuperación de los datos, salvo en puntuales referencias de alguna presentación didáctica general sobre la Prehistoria (como en sus lecciones del año 1918 o en su manual de 1932: J.M.de Barandiarán 1919 y 1932); hallándose sólo en su obra impresa simples alusiones de paso, y evidentemente muchos sobreentendidos, sobre esas cuestiones. Nuestra información sustancial sobre sus modos de recuperación de los yacimientos y materiales proviene fundamentalmente de dos fuentes: las reflexiones y consejos de la correspondencia que T. de Aranzadi le dirige al comenzar su actividad excavadora y los textos de sus memorias de excavación donde aquellos principios metodológicos se realizan. 
Además, quienes le acompañamos en la primera mitad de los 60 como colaboradores de sus excavaciones pudimos conocer y aprender los principios y aplicación práctica de un método de excavación realmente ejemplar con respecto a lo que entonces resultaba habitual entre los equipos de prehistoriadores de solvencia. Esos sistemas de excavación habían sido estructurados en los primeros trabajos de 1917 y siguieron aplicándose, con las necesarias puestas al día, en sus últimos trabajos de inicios de los 70 .

Vale la pena leer la correspondencia que dirige Aranzadi a Barandiarán en los meses en que se empezaba a desarrollar su importante empresa de excavaciones prehistóricas en el País Vasco; el 9 de octubre de 1916 se fecha la primera de las cartas que Aranzadi le envía (ofreciéndole una total colaboración científica y su integración en su equipo de excavaciones, junto a Eguren), el resto de las cartas más interesantes (L.de Barandiarán 1989: 7, 8, 10, 15, 20 y 26) se escribió en los meses en que se estaba preparando la primera campaña de excavación en dólmenes (son, además de ésa del 9 de octubre, las del 18 de octubre y 14 de noviembre de 1916, y de los días 23 de abril y 5 de agosto de 1917) o poco antes de iniciarse la segunda (el 12 de junio de 1918).

En esas densas e intencionadamente prolijas cartas de Aranzadi se enuncian las cuestiones fundamentales implicadas en la excavación de monumentos megalíticos. Los temas son planteados con claridad y resueltos con preocupación por el detalle y por asegurar la recuperación íntegra y correcta de los datos. Lo explícito de las apreciaciones literales de T.de Aranzadi ahorra prácticamente cualquier tipo de glosa pues ilustran sobradamente las intenciones y método de las excavaciones de Aranzadi, Barandiaran y Eguren, que se caracterizan porque:

1. Conocen bien la normativa de la autorización de excavaciones, las gestiones precisas para obtener una subvención oficial y los compromisos que de ellas se derivan ?

7. “... Conviene que "Euskalerriaren-alde" no divulgue la noticia (nota: se refiere Aranzadi al hallazgo de dólmenes que J.M.de Barandiarán dio a conocer, siendo éste su primer texto referido a la Prehistoria vasca, en un artículo que publicó en 1916 la revista "Euskalerriaren-alde" de San Sebastián, en las pp. 561-565 de su volumen 6, con el título de "Monumentos del Aralar guipuzcoano"), porque además de las razones que V. oportunamente expone, hay las de que está prohibido explorar monumentos sin previa autorización. Los de la parte navarra del Aralar los exploré, no ya con autorización, sino con subvención de la Diputación Foral de Navarra ..." (9 de octubre de 1916).

... En vista de lo que me decía en su atenta del 3 del corriente y después de esperar algunos días escribí a D. Pedro Manuel de Soraluce (nota: Soraluce fue director del Museo Municipal de San Sebastián e intervino decisivamente, en las dos primeras décadas del siglo, en la promoción de las investigaciones arqueológicas en Guipúzcoa), sin esperar ya más dándole cuenta de este asunto y del problema de las pesetas, haciéndole algunas indicaciones cuantitativas, aunque no ultimadas y expresándole mi confianza de que sabrían llevar la cosa por buen camino sin tropezar con celos y rivalidades en la Comisión de Monumentos, advirtiéndole además que no podemos pedir subvención a Madrid, porque en ese caso a Madrid irían a parar huesos y objetos hallados (nota: así sucedió, p.e., con los resultados de las excavaciones que por esos años llevaba a cabo el Conde de la Vega del Sella en yacimientos asturianos, cuyos hallazgos se depositaron en el Museo Nacional de Ciencias Naturales de Madrid, donde estaba la sede de la Comisión de Investigaciones Paleontológicas y Prehistóricas que subvencionaba los trabajos), item más que lo resolverían Dios sabe cuándo.

No he tenido contestación; quizás estén templando gaitas, no porque haya quien quiera disputarnos el privilegio de pasar noches en el monte y comer babarrunas guisadas por pastor o carbonero, sino porque les parezca escandaloso que trabajemos de balde cuando los comisionados del Gobierno tienen dietas en Numancia para el hotel de Soria (nota: se refiere Aranzadi a las excavaciones que entre 1906 y 1923 efectuó en ese yacimiento una comisión de arqueólogos dirigida por J.R.Mélida). Si estuviese en San Sebastián para conversar con Don Pedro (Soraluce), ya me contaría los tropiezos que haya, si los hay; pero desde lejos no es posible sacarle secretos y tampoco me serviría de nada. Ellos podrán trabajar para nosotros en ese terreno, pero no podemos en eso hacer nada los que estamos lejos, como no sea la solicitud cuando la fruta esté madura ..." (14 de noviembre de 1916). 
2. Calculan al detalle los costos de los trabajos y las necesidades del equipo humano y material que se requieren ${ }^{8}$.

3. Poseen una idea muy clara del plan de trabajo a seguir, con la estrategia y metodología del proceso de la excavación ${ }^{9}$.

8. “... Comprenderá .V. que la estancia, en la hospedería del Santuario (nota: de San Miguel in Excelsis, en el Aralar navarro), de todo el personal y la colaboración de carretas para llevar tienda de campaña, palancas, crics o gatos, picos, palas, azadones, azadillas, paletas, cedazo, latas, cajas, metro, cámara fotográfica, etc. etc., caballerías para mis compañeros (que tienen la suerte de poder cabalgar), guía, canteros y carpintero y chicas para el recado de la comida, el cernido y el cuidado de las caballerías, no son cosas que salgan de balde; esto último sí resulta en cuanto al trabajo mío y de mis compañeros ... claro es que si no hace falta remover la tapa, los crics o gatos y los dos canteros no son indispensables, y en vez de canteros y carpintero bastan unos peones de la aldea ..." (9 de octubre de 1916).

“... La distancia de tres horas de camino es muy grande; añada V. otra para el almuerzo y son siete. Dudo que haya ningún pueblo más cerca que Ataun, como no sea el barrio de Aya, pero ¿no habría siquiera alguna borda donde pasar las noches? Por mi parte veo la posibilidad de dormir en tienda de campaña, si la tuviésemos; pero supondría su transporte a la proximidad de cada dolmen. En nuestras exploraciones de 1913 y 1915 tuvimos la de la Cruz Roja de Pamplona porque mi compañero Ansoleaga es el Presidente (nota: se trata de Florencio de Ansoleaga, con quien Aranzadi excavó en 1913, 1915 y 1916 un total de diecinueve dólmenes del Aralar navarro, que publicaron en 1915 y 1918); nos sirvió para guardar herramientas, cajas, latas, etc. y para cobijarse el guarda de noche, y si el tiempo se ponía feo, también nosotros ... Esta necesidad de paciencia hace que no se pueda hacer la exploración de cada dolmen bajo la norma de un viaje en un día de 3 horas de ida y 3 de vuelta y por consiguiente único. Habrá alguno que no dé nada o casi nada, pero es para verlo después de explorado con calma y en tal caso bastaría para ello quizás un día; pero en caso de dormir a menor distancia que en Ataun. En el monte del Estado y muy cerca de la raya de Guipúzcoa, pero dentro de la provincia de Navarra, vimos algunos dólmenes destapados, que no exploramos por estar muy lejos y porque los destapados tienen muchas menos probabilidades de dar hallazgos, alguno ni siquiera dientes en cantidad apreciable ..." (18 de octubre de 1916).

“... Me escribió desde Oviedo (Universidad) D.Enrique Eguren en cuanto leyó el artículo de V. preguntándome si se podrá hacer algo el verano, en la confianza (¿cómo no?) de que no faltarán ánimos y planteando el problema de las pesetas. El año pasado había estado con nosotros en San Miguel de Excelsis; claro que no es lo mismo dormir, desayunar y cenar en aquellas condiciones que hacer vida pastoril en chabolas, pero Eguren es joven, animoso y acostumbrado a exploraciones prehistóricas en Alava hasta Oquina y Salvatierra ... Los jornales que dimos este verano a los de Huarte-Araquil fueron de 5 al guía-pastor, pero de 3 a los dos peones; es verdad que dormían y comían a nuestra cuenta en San Miguel ... " (14 de noviembre de 1916).

“... No olvidar tampoco el cómputo de lo que tardamos en llegar, para las necesidades prácticas de la vuelta y de los días sucesivos ... " (5 de agosto de 1917).

9. “... En este primer recorrido quizás conviniera señalar los dólmenes en situación del plano y fotografiarlos, de modo que quedarían señalados en el punto correspondiente del plano y marcada la orientación de la entrada con la brújula en correspondencia con la numeración de la placa y el nombre del dolmen. Si diera tiempo también se podrían medir por fuera las piedras en las que lo permitieran y no lo hubiera $\mathrm{V}$. hecho ya el año pasado, en espera de medir por dentro cuando se hiciese la excavación; si no hubiera tiempo para ello quedaría esto para la otra visita al mismo dolmen. Pero si el tiempo estuviese algo fresco y no diera probabilidades de éxito a la fotografía, podríamos invertir los términos, es decir, en la primera visita orientar y medir y en la segunda fotografiar. Aun orientando la entrada, conviene también señalar la orientación de la cámara fotográfica, cosa que se me pasó por alto en Navarra (nota: se refiere Aranzadi a las excavaciones que realizó en el Aralar en 1913, 1915 y 1916) porque habíamos adoptado el sistema de fotografiar por los 4 puntos cardinales; pero siendo muchos los dólmenes y el terreno dificultoso, convendrá ahorrar placas, eligiendo el punto de vista que dé más detalles, aunque no sea cardinal y señalando los grados de la brújula de la orientación de la cámara fotográfica ... " ( 23 de abril de 1917).

“... En los destapados (nota: alude Aranzadi a los monumentos destapados y, por ello, probablemente revueltos o saqueados por aldeanos o pastores) son mucho menores las probabilidades de hallazgo. En los tapados y con piedras de pared 
4. Saben que la rentabilidad de una excavación se reconoce por la calidad del máximo de datos, del tipo que sean, recuperados en un yacimiento y no tanto por el valor que a algunas piezas concretas completas o más aparentes se les puede atribuir como elementos coleccionables y de exposición en museos ${ }^{10}$.

5. Insisten reiteradamente en la necesidad de disponer de un utillaje especializado, tanto para la extracción y cribado de las evidencias como para la mayor seguridad de su embalaje y conservación ${ }^{11}$.

inclinadas a un lado hay que procurar evitar el que se nos vengan encima al ahondar en el hueco; éste no hace falta que se ahonde más que hasta lo más bajo de las piedras de las paredes, pero faltando el relleno podría escurrirse la que estuviere más adentrada por abajo, por lo que hay que pararla con una o dos ramas gruesas atravesadas y ajustadas. El haberlos revuelto antes manos profanas no es pronóstico seguro de que nada se encuentre, sobre todo en el cernido de la tierra; lo que nada vale para un casero de Amézqueta puede valer para el estudio ..." (14 de noviembre de 1916).

“... Respecto del cursillo de Prehistoria (nota: se refiere Aranzadi al cursillo de Prehistoria que Barandiarán iba a impartir, poco después, en Oñate, en el Primer Congreso de Estudios Vascos; ahí precisamente Barandiarán hará alusión muy cuidadosa a las técnicas de recogida, utilizando reiteradamente el prolijo manual de investigaciones de la Sociedad Prehistórica Francesa de 1906) no se olvide de hacer frente al método Rotondo Nicolau de los coleccionadores, hacer incapié en la importancia de la estratigrafía a tiempo, de la revisión escrupulosa con cernido, etc., de recoger lo que en el primer momento puede parecer inútil, de no meter mano sin armarse antes de mucha escrupulosidad; pues en esta Ciencia los apresurados pueden cometer daños irreparables. Claro es que vendrá bien ilustrar todo con ejemplos del país; pero al hablar del método Rotondo Nicolau puede V. dejarlo sin bautizar (nota: La justa crítica de Aranzadi se dirige contra Emilio Rotondo Nicolau, al que se alude en un periódico de ese tiempo como director del "Museo prehistórico de Madrid", y que estuvo relacionado con el Museo de San Sebastián donde clasificó algún resto paleontológico y practicó catas diversas en Guipúzcoa, sirviendo de ejemplo a Aranzadi de una actuación de coleccionista rechazable en Prehistoria. Especialmente se relacionó Rotondo Nicolau con el importante yacimiento paleolítico de la cueva de Aitzbitarte, donde hizo varias catas entre 1902 y 1906, a veces interviniendo en el equipo que coordinaba P.M.Soraluce, animador siempre de una intervención sistemática y a fondo en Aitzbitarte, como la que estuvo a punto de llevar adelante el Institut de Paléontologie Humaine de París, bajo la dirección de H.Obermaier y J.Bouyssonie, en 1911. Es así como los intereses del coleccionista Rotondo Nicolau habían de chocar frontalmente con la preocupación de la Comisión de Monumentos de Guipúzcoa por una excavación metódica: el 27 de setiembre de 1913 dirigió Rotondo Nicolau una instancia al Gobernador Civil de Guipúzcoa solicitando permiso de excavación de la cueva de Aitzbitarte a su favor, corriendo él mismo con los gastos y "comprometiéndose a entregar los objetos duplicados que encuentre al Museo de esta provincia", ante lo que la Comisión de Monumentos de Guipúzcoa intervino de seguido el 11 de enero de 1914 recordando sus competencias y autoridad en la aplicación de la Ley de 1911 y poniendo dificultades a la solicitud de Rotondo); después de todo no creo que sea el único culpable ... “(12 de junio de 1918).

10. "... No haciendo falta mover de su sitio más que piedras del galgal y otras equivalentes del relleno interior, no se necesitan grandes herramientas, pero sí mucha paciencia. Hay objetos que no abultan más que una lenteja y que pueden resultar de valor arqueológico; otros cuyos fragmentos pueden ser de menor tamaño aún y que reunido den un total o la mayor parte de un objeto. De aquí la necesidad de cerner con un cedazo de mallas no muy anchas ni tampoco excesivamente finas para impedir el paso de la tierra desgranada. Este año he encontrado hasta 15 pedazos de una calavera, que me ha permitido, pegándolos con cola más tarde en los sitios correspondientes, armar una bóveda craneal, sin duda ninguna en cuanto a su correspondencia individual y de posición; si los hubiera abandonado por menudos e inútiles para estudiar nada en ellos, eso hubiera perdido ... " (18 de octubre de 1916).

“... Para pedir dinero hay que tener esperanzas de encontrar algo, aunque no sean más que algunos huesos útiles para el estudio, algunos pedazos de cacharro, algún cuchillo o punta de flecha de pedernal, alguna cuenta de collar y quizás algún pedazo de punzón o pulsera de cobre o bronce, bolitas de mineral y cristal de roca. Pero de todos modos, el sacar fotografías, determinar la situación y orientación, trazar la planta y medir las piedras de cada dolmen, resultado estimable es .... " (14 de noviembre de 1916).

11. “... El cedazo más conveniente es el de malla metálica de medio centímetro, con cerca de unos 40 de diámetro y 10 de alto ... " (14 de noviembre de 1916).

“... Tengo idea de que hace mucho tiempo dije a V. ya algo respecto a los instrumentos necesarios y convenientes; entre 
6. Cuidan recoger suficientes referencias topográficas (de cartografía general y planos) y fotográficas de los yacimientos ${ }^{12}$.

Para valorar con más detalle el trabajo de campo de Barandiarán en los años 1917 a 1936 se puede examinar el contenido de sus memorias de excavación - referidas tanto a dólmenes como a niveles de habitación en cuevas - y la entidad de los datos recuperados en esos yacimientos. Aseguramos (I.Barandiarán 1988: 71-72) que en el desarrollo de la investigación sobre cualquiera de esos sitios:

1. Se organiza el espacio del yacimiento a excavar, preparando un plano general al que se refieren profundidades y disposición en planta de las evidencias y en el que se sitúan las áreas excavadas con los niveles y estructuras apreciados. Ya en la campaña de 1918 de la cueva de Santimamiñe se trabaja con un plano $\emptyset$ horizontal de referencia cartográfica; $y$, tanto ahí como en las excavaciones posteriores (en las cuevas de Ermittia, Urtiaga, Bolinkoba y otras) se subdivide la planta del yacimiento en zonas, tramos o sectores de superficie rectangular o cuadrada y, por tanto, exactamente encajable en un plano general. En la excavación de la cueva de Silibranka, en 1930, se trabajó ya con cuadrícula de $1 \mathrm{~m}$. de lado, levantando el depósito, a partir de la estratigrafía natural del lugar, en tramos de $10 \mathrm{~cm}$. de espesor.

ellos del cedazo y tamaño de su malla, pero no recuerdo si le hablé de una azuela de mango corto y de una paleta parecida a la de los albañiles para escarbar "kontu kontu" dentro del dolmen y recoger las pequeñas porciones de tierra que se han de cerner ... “ (23 de abril de 1917).

“... Conviene que lleve V. además de las azuelas una especie de paleta parecida a la de los albañiles, cajas de hojalata de las de galletas tamaño grande por si hay calavera y porque dentro de una de ellas se pueden llevar muchas cajas pequeñas. Yo tengo en el baúl una porción de cajas de hojalata de las de Pithinés, que sirven para guardar dientes, cuentas de collar, cuchillos y puntas de flecha de pedernal, etc. También nos convendría llevar papeles, aunque sean periódicos ... " (5 de agosto de 1917).

12. “... Conviene proporcionarse un plano del término municipal para calcar de él lo necesario y situar los dólmenes, una vez que ya explorados no haya miedo de que nos los echen a perder ... “ (18 de octubre de 1916).

“... El año pasado llevó Eguren una cámara prestada que nos dió mico, pues por defectos de la disposición para escamotear las placas, se echaron a perder todas las impresionadas; así, pues, conviene ensayar previamente la que se haya de llevar. Es ese uno de los capítulos que da muchos disgustos y chascos. Si puede conseguir copia del plano de los montes de Ataun por anticipado, nos será muy útil para señalar cada dolmen en el acto, que es lo más seguro y mejor ... “ (14 de noviembre de 1916).

“... Conviene un metro pintado, que puede V. encargar en esa; se reduce a un listón de un metro de largo, con los decímetros pintados alternativamente de blanco y negro. Sirve para colocar bien visible en el primer término del dolmen al fotografiar éste ... Así pues, en la visita primera de inspección serán nuestros acompañantes la o las cámaras, la brújula, el barómetro de alturas (que me dijo Eguren que V. tenía), el listón-metro, el metro plegable o en cinta y el plano. Estoy esperando que me envíen de Navarra el plano de los alrededores de San Miguel al 1/20.000 probablemente, de modo que llegará un día en que se puedan relacionar en posición los dólmenes que hay desde Madoz hasta Ataun, a todo lo largo del Aralar; y todavía nos quedarán fuera de cuenta los de Putherri, Baraibar, Gainza y Huici de Navarra ... “ (23 de abril de 1917).

“... Creo que habíamos quedado en que lo primero sería determinar la situación en el plano, altitud con barómetro, orientación con la brújula, fotografía del mejor punto de vista y su orientación con la brújula, así como no olvidar al impresionar la colocación visible de la regla-metro; luego medidas de las piedras en las que no lo hubiese V. hecho antes, medida del diámetro del montón de piedras con una cinta métrica que llevo yo ... " (5 de agosto de 1917).

“... De aquí a fin de mes podremos precisar más por carteo, como le decía a D. Enrique, sobre todo para lo que primero hemos de hacer. Conviene ir preparando los adminículos y ya le encargaré varias cosas a él; pero se me olvidó decirle nada del metro pintado con centímetros blancos y negros; si lo tiene V. a mano no hará falta más; pero sí convendrá en la misma forma otro listoncillo de unos veinte centímetros con las alternativas de blanco y negro, por si se fotografía alguna figura en que quepa poner al lado ese listón. Puede V. pues encargarlo. No se olvide de brújula, barómetro y lámpara, pues estas cosas son tales, que a lo mejor fallan y no se puede estar pendientes de lo que un solo instrumento no diga ... " (12 de junio de 1918). 
2. Se emplea en el descubrimiento y extracción de las evidencias muebles una herramienta menor ("a punta de raspador" - nombre de un instrumento metálico característico -, se precisa en varias memorias) y se pasa por criba toda la tierra extraída.

3. Se conserva todo el ajuar arqueológico y los restos óseos de antropología y macromamíferos y se tiene cuidado en retener muestras complementarias suficientes (p.e. de tierras, petrología, conchas, etc.)

4. Se cuida de dejar siglado todo el material recogido con indicaciones (sobre sí y otra complementaria en los paquetes) que permiten conocer sin duda su procedencia (en cuanto a fecha de la extracción y nivel, profundidad y situación en la planta del yacimiento) y referirlo posteriormente tanto a las anotaciones de la memoria como al diario de excavaciones.

5. Se publican las memorias con los resultados de la excavación y sus interpretaciones con notable celeridad, con bastante detalle de datos y con suficiente aparato gráfico. Más aún el análisis de los restos arqueológicos (de los que se responsabilizaba Barandiarán) viene acompañado en esos textos de buenos estudios de antropología física (aportados por Aranzadi) y de suficientes referencias de medio ambiente y de fauna (elaboradas por Eguren, con eventuales aportaciones de otros especialistas, p.e. en peces o aves). La estructura de esas memorias experimentó al paso del tiempo un cambio de orientación, que no vamos a analizar más a fondo. Las primeras memorias publicadas (así las dolménicas o las de las excavaciones de las cuevas de Santimamiñe y Lumentxa: es decir, las que recogen los trabajos de 1917 a la primera mitad de los 20) siguen el esquema de crónica de lo realizado en los días en que se va desarrollando la excavación; las memorias posteriores (como las de Ermittia, Bolinkoba y Urtiaga) se articulan en torno a la descripción en secuencia del depósito de los niveles descubiertos.

\section{b.2. En los años 1954 a 1974}

Durante los veinte años de la segunda época de los trabajos de campo de Barandiarán (concretamente entre el inicio de las nuevas campañas de excavación de Urtiaga en 1954 y sus últimas actuaciones en Ekain en 1972 y Axlor en 1974) se mantiene el rigor en la recogida de los datos (es decir, la propia excavación) y el cuidado en su transmisión (mediante los textos que describen el proceso de la excavación y sus resultados).

En este tiempo se aplica estrictamente el sistema de las coordenadas cartesianas (con cuadrícula y referencia al plano 0 , control tridimensional de los datos y extracción por tallas), se utiliza un utillaje menor (cuchillos, raspadores y punzones, brochas,...) para el levantamiento de los niveles y recuperación de las evidencias muebles, se criba con cedazos de trama reducida toda la tierra extraída, se conservan todos los restos antrópicos y de fauna y se retienen muestras suficientes de los elementos contextualizadores de lo arqueológico.

En cuanto a la conservación de lo recuperado en esas campañas: se inscribe sobre cada pieza con sigla individual la referencia de las circunstancias de su hallazgo (yacimiento / cuadro y, eventualmente, sector / profundidad / número de registro en el nivel), se deposita la totalidad de lo recuperado en fondos de museos públicos y se produce la pronta publicación (normalmente en fascículos, por cada campaña, en el caso de trabajos dilatados en el tiempo) de las memorias de excavación. En estas memorias se ofrece siempre una concreta definición de los niveles determinados (como depósito y como continente cultural), un listado completo de las evidencias arqueológicas con su correcta identificación tipológica (con dibujo de todas las piezas clasificables), una referencia suficiente sobre las especies animales presentes en cada nivel y sobre las condiciones especiales del depósito de algunos yacimientos (como, p.e., las de la cueva de Atxeta o del dolmen de San Martín) y un repertorio gráfico complementario discreto de planos, cortes y fotografías. Tales memorias de excavación son escuetas y ceñidas a la descripción de los hechos controlados inmediatamente en el proceso de la excavación; no incluyen análisis e interpretaciones complementarios (series de dataciones absolutas o 
estudios de arqueozoología, paleobotánica y sedimentología) que hoy parecen imprescindibles en una monografía de estudio integral de un yacimiento (¡de hecho, sólo empezaremos a encontrarlos en algunos de los textos publicados por otros prehistoriadores a lo largo de los 70!).

Las memorias publicadas y nuestro conocimiento directo de las excavaciones de J.M. de Barandiarán entre 1954 y 1972/74 nos permiten asegurar la gran coherencia del trabajo y la corrección de su metodología, que destacan especialmente por encima de los usos habituales en esos años en la Prehistoria occidental. Hay que reconocer su importante contribución a la actualización de los métodos de recuperación de datos en la Prehistoria peninsular, destacando tres aspectos especiales de la modernidad de sus sistemas de trabajo:

$1^{1}$. Que fue uno de los primeros arqueólogos que se sirvió de 'coordenadas cartesianas' en la excavación de yacimientos prehistóricos en la Península Ibérica. Lo hace ya en sus campañas de la segunda mitad de los 50 (como en las cuevas de Urtiaga, Lezetxiki, Atxeta o Aitzbitarte IV); mientras que ese sistema de control arqueológico sólo dentro de los 60 empezaría a utilizarse en la excavación de algunos otros lugares de la cornisa cantábrica, generalizándose al final de los 70 a los yacimientos prehistóricos peninsulares (en cuya difusión tuvieron notable protagonismo los prehistoriadores y equipos formados en las excavaciones que dirigieron en los 60 J.M.de Barandiarán y en los 70 sus inmediatos colaboradores).

$2^{\underline{o}}$. Que, del mismo modo, en las excavaciones de mediados los 50esos años de J.M. de Barandiarán se puso en práctica el inventario individualizado de cada evidencia (que ahora parece imprescindible en toda excavación 'moderna'): conservando todos los datos de procedencia (consignados tanto en fichas sobre las bolsas o recipientes que contienen los elementos como en hojas formalizadas de registro general) que se articulan en entradas del diario de excavación y se consignan con sigla detallada inscrita sobre cada uno de los materiales.

3․ Que es evidente el interés que tiene para la Prehistoria del Sudoeste europeo la puntual publicación de los resultados de sus excavaciones en yacimientos muy importantes (cuevas de ocupación del Paleolítico medio al Mesolítico y dólmenes) y su adecuada conservación en colecciones públicas. Lo cual contrasta con lo sucedido a bastantes de las memorias de sitios peninsulares muy interesantes excavados en los 50 y 60 , que o no han sido todavía publicadas o lo fueron muy parcialmente: así ocurrió con El Pendo (cuyas excavaciones de 1953 a 1957 no fueron publicadas por sus responsables sino, más de veinte años después, por otros investigadores que, con gran dificultad, han intentado reconstituir los resultados de aquellos trabajos), en Cueva Ambrosio (de la que se ha publicado, dos décadas después y por otro arqueólogo, el resultado de una de las seis campañas de excavación realizadas), o con El Cierro, Berroberría, Carigüela, Torralba o Ambrona (sitios importantes de los que se han escrito notas introductorias o referencias parciales, pero no las memorias completas definitivas).

\section{c. La estructura y contenido de las memorias de excavación}

Se puede analizar la organización y contenido de sus memorias de excavación de 1917 a 1936 para evaluar lo que suponen en el contexto de la Prehistoria de su tiempo. Para ello nos servimos del texto publicado sobre su primera aportación megalítica (de 1919) estudiando nueve dólmenes del Aralar guipuzcoano, de sendas memorias del trabajo en las cuevas de Ermittia y Lumentxa (de 1928 y de 1935) y del estudio del arte rupestre de Santimamiñe (de 1925): el primero de esos textos es buen ejemplo del tipo medio de sus memorias de excavación, con un esquema que se utilizará posteriormente con ligeras variantes de mejora; los otros tres serán comparados con otros de entidad similar escritos, más o menos por esos años, por los prestigiosos prehistoriadores H.Obermaier y Conde de la Vega del Sella. 


\section{c.1. El contenido de una monografía sobre megalitismo}

La memoria de nueve dólmenes del Aralar guipuzcoano es el primer texto publicado por Aranzadi, Barandiarán y Eguren sobre sus excavaciones. Los dólmenes fueron descubiertos por J.M.de Barandiarán en setiembre de 1916 y, acordada de seguido su exploración por el equipo que habían de integrar Aranzadi y Eguren con él, la Diputación de Guipúzcoa acogió la subvención de las excavaciones el 14 de diciembre de 1916; la preparación de la campaña fue objeto (como vimos antes) de una extensa y detallada correspondencia de Aranzadi a Barandiarán. La excavación se desarrolló en 13 jornadas de trabajo, del 16 al 29 de agosto de 1917, participando en ella los tres investigadores con tres obreros. El 13 de diciembre de 1917 se hizo entrega a la Diputación de la memoria de los trabajos, que esa institución decidió publicar el 30 de enero de 1918: primero en las páginas de la revista "Euskalerriarenalde" y posteriormente (con pie de imprenta de 1919), como volumen suelto: libro de formato medio (de $23 \times 16,5 \mathrm{~cm}$.), con 51 páginas de texto (en caracteres pequeños) más 29 láminas fotográficas en papel couché.

Su texto se organiza en cuatro partes. La primera, de "preliminares" (6 páginas), ofrece una descripción general de la estación dolménica y presenta la organización de los trabajos y los itinerarios. La segunda dedica 20 páginas a la descripción de los nueve dólmenes excavados, detallándose: su situación y paisaje circundante; estado actual, dimensiones y morfología; el proceso de la exploración y la relación sucinta de los hallazgos; y referencias etnográficas. La tercera (16 páginas) describe los ajuares recuperados que se agrupan en varios apartados: minerales y fósiles; pedernal; cerámica; metal; madera y cuerno de ciervo; antropología física (dientes; otros huesos); y dientes y huesos animales. La cuarta parte (2 páginas) presenta unas "consideraciones finales" de interpretación.

Como ilustraciones esa memoria ofrece 2 planos dibujados (uno general, a escala $1 / 48.000$, con los treinta y seis dólmenes del territorio Aralar/Aitzgorri que de setiembre de 1916 a 1918 había descubierto Barandiarán; el otro particular, a escala 1/13.600, con los nueve dólmenes excavados por los tres investigadores en la campaña de 1917) y 38 fotografías de bastante buena calidad (16 de ellas son de los monumentos - 7 de dólmenes antes de su excavación, otras 7 de los mismos una vez concluidos los trabajos, 1 del menhir de Supitaitz y 1 del "cromlech" de Oiduegui - , 2 etnográficas - de sendas chabolas pastoriles -, 4 de ajuares - 1 de cristales de roca, 1 de pedernales tallados y 2 de otros materiales - y 16 de restos humanos).

El desarrollo del texto es prolijo y mesurado, aportando algunas precisiones de importancia, como lo que atañe a tipología racial de los ahí inhumados, a cronología de los dólmenes (de "hace 4000 años") y a interpretación de los monumentos en su contexto cultural. Destaca, sobre todo, en esas páginas el cuidado de las descripciones formales de los sitios y ajuares. Son minuciosas las definiciones de los monumentos, dibujando y describiendo bien los elementos que los constituyen tanto en la cámara (cuyas piedras se dibujan y miden en altura, grosor y espesor en centímetros) como en el túmulo. También son muy precisas las determinaciones de antropología física (debidas a Aranzadi) y el listado concreto de piezas óseas recuperadas, a las que se dedican 5 páginas de la memoria y correctas fotografías de las evidencias mayores en las diversas normas requeridas. Barandiarán que, por su parte, es el responsable del estudio de los ajuares, ofrece un correcto diagnostico tipológico tanto de lo lítico (define "cuchillos", "puntas de flecha" con alusión a sus variantes, "alguna barrenilla" refiriéndose a algún dudoso perforador, y "raspador") como de lo metálico ("lezna ..., anillo... de bronce o cobre (el análisis resolverá este problema)"), acompañando sus fotografías de la correspondiente escala con regla milimetrada.

En cuanto a las comparaciones y citas bibliográficas son las justas y muy precisas para asegurar la apoyatura de la propia interpretación asentando la explicación de algunos aspectos propios de la estación dolménica estudiada. Así se hace referencia (en cuatro ocasiones) como comparación más inmediata a los monumentos conocidos poco antes a través de las exploraciones de F.de Ansoleaga y T.de Aranzadi en la vecina estación 
del Aralar navarro y se acude al refrendo de materiales incluídos en los corpora de G. y A.de Mortillet (en seis citas) y de J.Déchelette (tres citas). Mientras que, buscando paralelos a los peculiares incisivos humanos con su corona tallada en $\mathrm{V}$ del dolmen de Argarbi, se acude a bibliografía muy especializada y reciente: el conocido manual de E.Foy de 1908, la recopilación Kulturelemente der Menscheit de K. Weule de 1910 y la monografía de G.Montandon en los "Archives Suisses d'Anthropologie Générale" de 1914.

\section{c.2. Otras monografías}

Para evaluar otros tipos de textos sobre excavaciones podemos comparar las memorias de las excavaciones de Aranzadi y Barandiarán en las cuevas de Ermittia en 1928 y Lumentxa en 1935 y la del Conde de la Vega del Sella en 1930 sobre la cueva asturiana de La Riera. Los tres son yacimientos con niveles importantes del Paleolítico superior, de extensión y entidad parecidos; fueron excavados casi al mismo tiempo y se presentan en un tipo de memoria similar en cuanto a tratamiento escrito de los datos y repertorio gráfico de identificación complementaria .

La memoria de las excavaciones de Ermittia (T.de Aranzadi y J.M.de Barandiarán 1928) consta de 38 páginas de texto, en las que se incluyen 48 figuras, y de 25 láminas fotográficas más. Su contenido escrito se desarrolla en partes sucesivas: situación geográfica, circunstancias del yacimiento, proceso de la excavación, descripción de los niveles con sus industrias lítica y ósea, estudio de la fauna (mamíferos, peces y aves) y consideraciones finales. En el efectivo gráfico que acompaña el texto se ofrecen en dibujo 3 planos y 1 corte esquemático y el dibujo de 75 utensilios líticos y de 8 de industria ósea, además de 1 de otro elemento arqueológico y 2 de fauna; completándose bien con un amplio lote de fotografías ( 6 generales del lugar y del yacimiento, 2 de conjuntos cerámicos, 2 de varios otros elementos, 9 de conjuntos de fauna y otras en que se representan hasta 111 utensilios de industria ósea).

La memoria de las excavaciones de la cueva de La Riera (Conde de la Vega del Sella 1930) ocupa 46 páginas, en las que se incluyen 29 figuras: la mayoría son dibujos a línea de 1 plano y 2 cortes estratigráficos, representándose 74 utensilios líticos y 39 de industria ósea y 4 elementos arqueológicos varios; aportándose, además, un conjunto no amplio de fotografías, con 3 vistas del lugar y 5 de utensilios líticos.

La memoria de las excavaciones de Lumentxa (Aranzadi y Barandiarán 1935) se desarrolla en 52 páginas de texto, que incluyen 17 figuras, más 25 láminas fotográficas. Se han dibujado en esa memoria 2 planos y 1 corte esquemático de la estratigrafía, 96 utensilios líticos, 4 de industria ósea, 6 piezas de fauna y otras 3 evidencias arqueológicas; se completa ese repertorio de ilustraciones con la fotografía de 7 vistas del entorno y del yacimiento, 3 de antropología, 8 de conjuntos de fauna, 8 (de buena calidad) de lotes cerámicos y de 36 utensilios óseos y 2 de una muestra de arte mobiliar.

También la comparación de monografías sobre arte rupestre, la de la cueva asturiana del Buxu (Obermaier y Conde de la Vega del Sella 1918) con la de Santimamiñe (Aranzadi, Barandiarán y Eguren 1925), ofrece una entidad parecida de estructura, descripciones e imprescindible aparato gráfico complementario. El estudio de la cueva del Buxu consta de 42 páginas de texto, incluyendo 14 figuras, más 19 láminas fotográficas y 1 plano. El de Santimamiñe ofrece 50 páginas, en que se incluyen 37 figuras, más 8 láminas y dos planos. Las representaciones dibujadas (como calcos) del arte rupestre en ambas monografías son de muy buena calidad, con fidelidad a los originales.

En suma, examinadas memorias de excavación y estudios de yacimientos de similar contenido arqueológico, se evidencia la concordancia sustancial de objetivos, desarrollo formal y conclusiones en los trabajos científicos que en la década de los 20 y 30 firma J.M. de Barandiarán con respecto a los producidos por los investigadores de mayor garantía entonces en el panorama de la Prehistoria peninsular. 
En cuanto a las memorias de las excavaciones de Barandiarán entre 1954 y 1972/74, obviando aquí su comparación con textos similares contemporáneos (de pretensiones y desarrollo bastante dispares), valdrán los juicios de valoración que antes precisábamos, destacando cuánto suponen como contribución importante al repertorio de datos de la Prehistoria occidental. Pese a su estilo sobrio, ceñido estrictamente a la descripción de los hechos controlados directamente en la excavación del sitio, el estudioso encuentra en esos textos de J.M.de Barandiarán la suficiente información sobre los niveles determinados, el completo listado de las evidencias (que están bien identificadas tipológicamente y dibujadas en su totalidad) y una referencia suficiente a las especies animales asociadas.

Más aún, el investigador podrá completar las informaciones procedentes de esas excavaciones de J.M.de Barandiarán, cotejando las precisas referencias de sus memorias con las colecciones correspondientes que se conservan ahora: en su totalidad, en depósitos públicos, bien ordenadas e íntegramente sigladas. Lo que, por desgracia, no puede asegurarse de los resultados de bastantes otras excavaciones realizadas modernamente.

Por otra parte, el total de los diarios ('cuadernos de campo') y documentación inmediata (planos e inventarios) producidos en esas excavaciones se conservan, a disposición del investigador, en los fondos de la 'Fundación José Miguel de Barandiarán' de San Gregorio de Ataun (Guipúzcoa).

\section{d. Valor de los datos aportados}

Los datos reunidos por Barandiarán a lo largo de casi sesenta años de investigaciones sobre la Prehistoria vasca se ordenan en varios lotes: los sitios descubiertos, los yacimientos excavados, las colecciones de elementos aportados a los museos, sus memorias de excavación y, finalmente, sus textos de interpretación y síntesis.

No es éste el lugar de detallar su amplio listado, por lo dilatado e intenso de su dedicación a la empresa. Acudiré a dos ejemplos concretos para significar el interés de los sitios y colecciones que debemos a la tenacidad y saber de J.M.de Barandiarán.

El primero considera el estado del conocimiento sobre el Paleolítico medio y superior en las provincias vascas. Una selección al día de los yacimientos más interesantes de ese ámbito de la Prehistoria retiene veinticuatro como sitios en cueva o abrigo rocoso bien estratificados y conocidos mediante sondeo y excavación que han aportado suficientes evidencias arqueológicas y contextuales: seis están en Vizcaya (Arenaza, Atxeta, Santimamiñe, Lumentxa, Axlor y Bolinkoba), uno en Alava (Arrillor), nueve en Guipúzcoa (Lezetxiki, Labeko Koba, Urtiaga, Ermittia, Amalda, Erralla, Ekain, Aitzbitarte III y Aitzbitarte IV), cinco en Navarra (Coscobilo, Mugarduia Sur, Abauntz, Berroberría y Zatoya), uno en Laburdi (Olha), uno en Baja Navarra (Isturitz) y uno en Zuberoa (Gatzarria). En la mitad de esos sitios la intervención de J.M.de Barandiarán ha sido decisiva: o porque fueron excavados sistemáticamente por él, como ocurre en el caso de los yacimientos de Santimamiñe, Lumentxa, Bolinkoba, Atxeta y Axlor (o sea, cinco de los seis vizcainos) y Ermittia, Urtiaga, Lezetxiki, Aitzbitarte IV y Ekain (o sea, cinco de los nueve guipuzcoanos) o porque fue él quien los descubrió o practicó en ellos prospecciones definitivas, como en los casos alavés de Arrillor y navarros de Abauntz y Coscobilo.

El segundo ejemplo se refiere al conocimiento que hoy disponemos sobre el megalitismo en Guipúzcoa. Según los datos de la más reciente carta arqueológica (Altuna et alii 1990) casi las dos terceras partes de los megalitos excavados en esa provincia lo han sido por J.M. de Barandiarán. A su trabajo de campo se debe la aportación de un total de cincuenta y un monumentos dolménicos cuya excavación fue llevada a cabo en su mayoría por Aranzadi, Barandiarán y Eguren entre los años 1917 y 1923 (son los de las estaciones de Aralar, Aizkorri, Altzania, Ataun-Borunda, Belabieta y Elosua-Placencia) o bien posteriormente (un dolmen en Murumendi en 1927 por Aranzadi, Barandiarán y Eguren y sendos en Altzania en 1960 y Txoritokieta en 1963 
por J.M.de Barandiarán). Mientras que de los restantes veintiseis megalitos excavados hasta 1990 en Guipúzcoa por otros equipos, poquísimos lo fueron inmediatamente antes o durante los años de la actuación de Barandiarán (así: algún cromlech de Oyarzun, donde trabajaron de 1909 a 1915 P.M.de Soraluce y T. de Aranzadi, un dolmen en Aratz-Alsasua por E. de Eguren en 1927, uno en Kurutzeberri por M. Alonso y los cuatro de IgoinAkola en 1950-51 por T. de Atauri, J. Elósegui y M. Laborde) y la mayoría, dieciocho, por las generaciones posteriores de colaboradores formados en su escuela (así: fueron excavados por J. Altuna, J.M. Apellániz y P.Rodríguez Ondarra entre 1963 y 1965 cuatro dólmenes de Satui-Arrolamendi, dos de Andatza, uno de Aralar y uno de Onyi-Mandoegi, por J. Altuna en 1967 y 1976 algunos cromlechs de Oyarzun y a partir de 1983 hasta ahora varios cromlechs de Onyi-Mandoegi por X. Peñalver y tres dólmenes de Murumendi, uno de Altzania y uno de Ataun-Borunda por J.A.Mujika).

Uno de los 'rendimientos' más evidentes del trabajo de José Miguel de Barandiarán se ha producido en los últimos veinticinco años por el necesario recurso que han debido de hacer a su obra bastantes de las tesis doctorales que han desarrollado investigaciones concretas sobre la Prehistoria vasca y la del ámbito mayor en que se inscribe este territorio (el Pirineo y la franja septentrional de la Península Ibérica). Así le son deudoras de un capital básico de datos, pues no hubieran podido llevarse a cabo en su entidad y conclusiones sin las informaciones que recogió y transmitió J.M. de Barandiarán, las tesis de algunos de sus colaboradores inmediatos de los años 60, las de varios de los que con ellos han trabajado más directamente y las de otros prehistoriadores que han estudiado los problemas de la Prehistoria en el territorio mayor en que se incluye el País Vasco ${ }^{13}$.

La aportación a las colecciones públicas de lo obtenido en las excavaciones de J.M.de Barandiarán se reconoce en la abundancia de los fondos de Prehistoria del Museo Arqueológico, Etnográfico e Histórico Vasco (Bilbao), del Museo Municipal de San Telmo (San Sebastián), y del Museo de Arqueología de Alava (Vitoria) y, en menor grado, los del Museo de Navarra (Pamplona).

\section{LA CONTINUIDAD DE LAS INVESTIGACIONES PREHISTÓRICAS DE JOSÉ MIGUEL DE BARANDIARÁN: LOS ELEMENTOS DE UNA 'ESCUELA'}

La obra y actitudes intelectuales de J.M. de Barandiarán, maestro directo indiscutible de la generación de los 60 y mediato de los grupos posteriores, tienen su plena continuidad en la 'escuela' que engloba a la mayoría de los equipos que ahora han asumido y llevan adelante la empresa del conocimiento de la Prehistoria vasca.

Su biografía evidencia una constante obsesión por ofrecer el resultado de las investigaciones y transmitir sus inquietudes y métodos de trabajo.

Barandiarán promovió y dirigió equipos de estudio y creó publicaciones especializadas: como el Seminario de Prehistoria "Ikuska" en Vitoria en 1921 (que en 1925 se constituye como "Centro de Investigaciones Prehistóricas" dentro de la Sociedad de Estudios Vascos), el "Anuario de Eusko-Folklore" en 1921, "Ikuska. Instituto Vasco

13. Así las Tesis de sus colaboradores de los años 60: Jesús Altuna, Juan M. Apellániz e Ignacio Barandiarán; las de aquellos otros que se formaron con ellos: Alfonso Alday, Teresa Andrés, Angel Armendáriz, A.Arrizabalaga, Amelia Baldeón, María Amor Beguiristain, Pedro M.Castaños, Ana Cava, Javier Fernández Eraso, César González Sainz, Geneviève Marsan, José Antonio Mujika, Andoni Saenz de Buruaga o Pilar Utrilla; o las tesis de otros investigadores que requirieron el recurso imprescindible a la obra de J.M.de Barandiarán, como las de Paul G.Bahn, Arianne Baulois, Soledad Corchón, Juan Fernández Tresguerres, Manuel R.González Morales, Mayor Ch.Mac Collough, Paulette Marquer o Lawrence G.Straus. 
de Investigación (Sección de Antropología)" en 1946 con su revista, el "Instituto de Investigaciones Arqueológicas Aranzadi" (origen del luego denominado "Arkeoikuska") en 1962 y los grupos de investigación etnográfica "Etniker" a partir de 1964 (promovidos desde su Cátedra de la Universidad de Navarra).

Por otra parte, ha producido sucesivos textos de revisión y síntesis que todos los interesados por estos temas hemos debido consultar. Unos son manuales de iniciación a la investigación, como la Breve Historia del Hombre Primitivo (en el "Anuario de Eusko-Folklore" de 1931) referido a las dos vertientes, prehistórica y tradicional, de la Antropología Cultural, o los Apuntes de Geología general y de la del País Vasco de 1932. Otros se refieren a los conocimientos que se van reuniendo sobre la Prehistoria del País Vasco: como su primera síntesis de envergadura El Hombre Primitivo en el País Vasco (edit. Itxaropena de Zarauz en versión castellana y euskera, Euskalerriko leen gizona) en 1934, el sistemático Catalogue des Stations Préhistoriques des Pyrénées Basques (en la revista "Ikuska") en 1946, El Hombre Prehistórico en el País Vasco (editorial Ekin de Buenos Aires) en 1953 y Lehen euskal gizona (editorial Lur de San Sebastián) en 1972.

La Sociedad de Estudios Vascos que en 1976, refundada en la segunda etapa de su historia, le eligió como su Presidente, promoverá en 1979 las bien dotadas “Becas de Investigación José Miguel de Barandiarán”, que financian a partes iguales las Diputaciones Forales de Navarra, Alava, Guipúzcoa y Vizcaya para subvencionar bianualmente trabajos en equipo de Arqueología y de Etnología, constituyéndose en 1989 la "Fundación José Miguel de Barandiarán" que vela por el conocimiento y continuidad de sus investigaciones.

Esa obsesión de Barandiarán por el mantenimiento de sus inquietudes y la continuidad de su obra científica se revela desde muy pronto y se va materializando en una variada muestra de aplicaciones y empresas de divulgación. Ya en los estatutos fundacionales del Seminario de Prehistoria "Ikuska" que creó Barandiarán en Vitoria en 1921 se definen las intenciones difusoras de su fundador: "aunar los esfuerzos de los investigadores, por una parte, y en un plano social fomentar estos estudios entre la juventud estudiosa y aleccionar al pueblo en el conocimiento y respeto de los restos arqueológicos". A lo largo de su vida supo compaginar sus obligaciones docentes con su intensa actividad de prospección, excavación y redacción de monografías y con una ejemplar labor divulgadora: organiza cursos, publica manuales y estados del conocimiento.

En el conjunto de colaboradores de los trabajos arqueológicos de J.M.de Barandiarán se distinguen varios grupos, a modo de generaciones, que se han ido sucediendo a lo largo del tiempo de su actuación y en el entronque de su 'escuela':

El primero, constituido por quienes le acompañaron en las prospecciones y excavaciones de los años 1917 a 1936: jóvenes estudiantes e interesados (maestros, curas o eruditos locales).

El segundo, lo forman quienes le ayudaron en sus trabajos de campo de los años 40 y 50 , tanto en el exilio como en los inicios de su renovada actividad excavadora en las provincias de este lado de la frontera: Georges Laplace o Pierre Boucher en sus investigaciones del País Vasco septentrional, Jesús Elósegui, Tomás de Atauri o Manuel Laborde en Guipúzcoa, Mario Grande en Vizcaya o Domingo Fernández Medrano en Alava.

En el tercero se integran quienes empezamos a colaborar directamente en la década de los 60 en las excavaciones de diversos yacimientos y en otras prospecciones complementarias que dirige J.M.de Barandiarán ${ }^{14}$. El "Instituto de Investigaciones Arqueológicas Aranzadi” (que Barandiarán creó en 1962), agrupando a quienes por entonces nos iniciábamos en la investigación de campo y laboratorio sobre la Prehistoria del País Vasco, consiguió una inteligente homogeinización de la metodología de las excavaciones y en los criterios de interpretación de las evidencias; las reuniones anuales del Instituto supusieron en esa década el elemento aglutinador

14. Tales Jesús Altuna, Ignacio Barandiarán, Francisco Fernández García de Diego, José María Merino o Pedro Rodríguez de Ondarra en Guipúzcoa, Juan María Apellániz, Armando Llanos, Jaime Fariña o Juan Antonio Agorreta en Alava, Juan Miguel de Ugartechea o Ernesto Nolte en Vizcaya, etc. 
de los grupos, facilitando el conocimiento e intercambio de opiniones sobre los trabajos en curso en los diversas provincias y planificando líneas y programas de investigación conjunta.

En el cuarto grupo se incluyen las generaciones más recientes, normalmente formadas en los centros de docencia o investigación donde se establecen a partir de los años 70 J.Altuna (Sociedad de Ciencias Aranzadi, en San Sebastián), J.M.Apellániz (Universidad de Deusto y Museo de Vizcaya, en Bilbao), I.Barandiarán (Universidades de Zaragoza y de Santander y, desde 1980, del País Vasco en Vitoria) y A.Llanos (Instituto Alavés de Arqueología, en Vitoria) o bien en los equipos muy relacionados con ellos que se articulan en Pamplona en torno a Enrique Vallespí (Universidad de Navarra), en Guipúzcoa con José María Merino y en Iparralde con Georges Laplace (Centre de Palethnologie Stratigraphique 'Eruri', en Arudy), Pierre Boucher o Jacques Blot. Estas nuevas generaciones cooperarán primero en las excavaciones y estudios que dirigen los que se habían iniciado directamente con J.M.de Barandiarán, actuando pocos años después como protagonistas de sus propios proyectos de investigación de campo y multiplicándose en otros grupos de trabajo ${ }^{15}$.

Con esa integración de los interesados en un proyecto desarrollado en las varias provincias, pero con una orientación y método comunes, se aseguró el fomento de los estudios sobre la Prehistoria vasca conforme la avanzada edad de J.M.de Barandiarán le iba obligando a reducir la intensidad de sus intervenciones arqueológicas de campo en la segunda mitad de los 60 y a concluirlas a comienzos de los 70 . En 1971 dirige Barandiarán sendas campañas cortas de prospección en las cuevas de Pikandita, Limurita y Kobalde y una más larga en la de Ekain, en 1972 comparte ya la dirección de la campaña anual (la cuarta) de Ekain con J.Altuna, en 1973 lleva a cabo sólo una campaña de excavación en Kobalde y, por fin, en julio de 1974 con 84 años de edad, excava en última campaña el yacimiento musteriense del abrigo de Axlor en el que venía trabajando desde 1967.

El progreso de los estudios prehistóricos en estas provincias se había producido hasta hace no mucho tiempo merced a la intervención de personas concretas más que a impulsos institucionales; puesto que la acogida de las entidades públicas a estas investigaciones fue algo puntual (o sea, dirigida a proyectos muy concretos de intervención y no generalizada a un territorio mayor) y de corto plazo. Sólo en las dos últimas décadas se desarrolla un proceso de 'institucionalización' de la Arqueología vasca, cuando la mayor parte de las personas y equipos de trabajo van consiguiendo la tutela habitual de organismos públicos donde se insertan y cuya gestión o asesoría acabarán asumiendo. Esto ocurre en departamentos y seminarios de la Universidad, en diversos servicios de conservación del patrimonio y promoción cultural de Museos y Diputaciones provinciales o en otras sociedades y grupos de estudiosos que habitualmente amparan y subvencionan esas instituciones. Casi todos estos centros disponen de laboratorios suficientemente equipados y con bibliotecas y editan revistas especializadas en la Arqueología y Prehistoria regional.

15. Son los que se van incorporando, a lo largo de los 80 , a aquellos y a otros centros de investigación (en las universidades, en museos o en sociedades de promoción de esos estudios) y que continúan la línea de los trabajos sistemáticos de J.M. de Barandiarán. En la primera generación de estos nuevos prehistoriadores y especialistas en ciencias afines están, entre otros, María Amor Beguiristain (Universidad de Navarra), Amelia Baldeón (Museo de Arqueología de Alava), Pilar Utrilla (Universidad de Zaragoza), Ana Cava (Universidad del País Vasco), Pedro Castaños (Museo de Bilbao), Geneviève Marsan (Musée de Préhistoire de Lourdes), Margarita Muñoz, Paquita Saenz de Urturi, José Ignacio Vegas, Koro Mariezkurrena (Sociedad Aranzadi) o Eduardo Berganza, siguiéndoles en el tiempo Javier Fernández Eraso (Universidad del País Vasco), Andoni Saenz de Buruaga (Universidad del País Vasco) José Antonio Mujika (Universidad del País Vasco), César González Sainz (Universidad de Cantabria), Angel Armendáriz (Universidad de Cantabria), Javier Peñalver (Sociedad Aranzadi), Francisco Etxeberria (Sociedad Aranzadi), Alfonso Alday (Universidad del País Vasco), Luis Ortiz Tudanca, Javier Gorrochategui, María José Yárritu, José Antonio Fernández Lombera (Universidad de Deusto), José Luis Arribas y otros. 
Hay algunos organismos públicos o privados a los que se deben aportaciones muy importantes al conocimiento de la Prehistoria regional. Es el caso de la "Institución Príncipe de Viana" creada en 1940 por la Diputación Foral de Navarra (que asume hoy todas las áreas del Servicio de Cultura del Gobierno Foral), de la "Sociedad de Ciencias Aranzadi" de San Sebastián fundada en 1947 y del "Instituto Alavés de Arqueología" que se crea en 1966 en Vitoria integrándose entonces en el Consejo de Cultura de la Diputación Foral de Alava (y hoy ha sido reducido a sociedad privada).

No existiendo en estas provincias hasta hace unas décadas centros de enseñanza superior que atendieran la docencia e investigación de la Prehistoria se debió el impulso de algunos proyectos a estudiosos de varias de las Universidades vecinas: como los promovidos desde el Institut du Quaternaire de la Universidad de Burdeos o desde el Departamento de Ciencias de la Antigüedad de la Universidad de Zaragoza.

Sólo avanzada la década de los 60 se han ido asentando los departamentos universitarios que en sus planes de estudio incluyen enseñanzas sobre la Prehistoria territorial y sus Ciencias afines y que desarrollan proyectos de investigación en campo y laboratorio. Es el caso del Seminario de Arqueología de la Universidad de Navarra en Pamplona y del Seminario de Arqueología de la Universidad de Deusto en Bilbao, que existen desde mediada la década de los 60, y del Departamento de Prehistoria y Arqueología de la Universidad del País Vasco en Vitoria, que se constituye a inicios de los 80.

En las instalaciones y servicios de los Museos públicos su personal atiende a la conservación de los datos recuperados y de los correspondientes fondos bibliográficos y documentales, coordina muchas intervenciones de urgencia y desarrolla sus propios planes de investigación. La práctica totalidad de los materiales de la Prehistoria de Navarra, Alava, Guipúzcoa y Vizcaya se conserva en los fondos públicos de los Museos de Navarra en Pamplona, de Arqueología de Alava en Vitoria, Municipal de San Telmo en San Sebastián y Arqueológico, Etnográfico e Histórico Vasco en Bilbao. Mientras que las evidencias de Prehistoria del territorio septentrional se guardan en lotes de diversa entidad: como las series menores del laboratorio del Liceo y del Musée Basque de Bayona, las de Olha I e Isturitz que custodia el Musée des Antiquités Nationales en St.Germain-en-Laye y las colecciones particulares de P.Boucher en Mauleon, C.Chauchat en Bussunaritz, G.Laplace en Coarraze y J.Blot en San Juan de Luz, etc.

Investigadores del Centre National de la Recherche Scientifique de Francia (G.Laplace desde su centro de Arudy y C.Chauchat del Institut du Quaternaire de Burdeos) dirigen trabajos de campo e investigaciones sobre la Prehistoria de la vertiente septentrional del Pirineo.

Varias revistas de entidad consolidada acogen las investigaciones sobre la Prehistoria vasca: excavaciones y prospecciones, revisiones de materiales, síntesis o monografías sobre temas concretos. Promovidos por universidades, museos y sociedades de investigación son frecuentes los ciclos, cursos y seminarios de especialización que exponen las novedades técnicas y metodológicas de la Arqueología prehistórica. Por otra parte empieza a ser habitual que congresos y reuniones organicen secciones dedicadas a plantear las cuestiones de la Prehistoria regional y de las ciencias convergentes ${ }^{16}$.

16. El "Bulletin du Musée Basque de Bayonne" se empezó a publicar en 1924, la revista "Munibe" de la Sociedad de Ciencias Aranzadi de San Sebastián en 1949, la revista "Kobie"(patrocinada por la Diputación de Vizcaya) en 1969, los monográficos "Cuadernos de Deusto" de su Universidad en 1974, la revista "Veleia" del Instituto de Ciencias de la Antiguiedad de la Universidad del País Vasco en Vitoria en 1984 y los "Cuadernos de Arqueología de la Universidad de Navarra" por ese Centro en Pamplona en 1993. La Sociedad de Estudios Vascos mantiene dos tipos de publicaciones regulares al respecto: los "Cuadernos de Sección" correspondientes a las de Prehistoria y Arqueología que se publican desde 1982, y la Serie B (que incluye los estudios desarrollados en los planes de las Becas de Investigación J.M.de Barandiarán) desde 1984. Por otro lado, los contenidos de Prehistoria y Arqueología que publicaban en Pamplona la revista "Príncipe de Viana" (desde 1940) y la serie "Excavaciones en Navarra" (desde 1942) han sido asumidos desde 1979 por la revista "Trabajos de Arqueo- 
Las instituciones de gobierno de la Comunidad Autónoma Vasca (buena parte de sus competencias al respecto han pasado, por la Ley de Territorios Históricos, a las Diputaciones de Alava, Vizcaya y Guipúzcoa) y de la Comunidad Foral de Navarra tienen hoy la responsabilidad de la conservación del respectivo Patrimonio arqueológico. Son ellas quienes regulan la concesión de permisos de excavación y de subvenciones a esos trabajos, cuidan los yacimientos y conservan en los museos públicos los materiales obtenidos.

Los proyectos de investigación sobre yacimientos arqueológicos (a los que se dedican equipos bien preparados de la Universidad y de algunos museos y sociedades privadas) hasta hace muy poco eran suficientemente subvencionados: en los últimos años empiezan a experimentar en alguna provincia recortes que impiden su adecuado desarrollo. La dotación de esos centros en equipo humano y material es hoy sustancialmente superior a la de hace un par de decenios, pero ya no alcanza a cubrir la amplia demanda de ayudas para la formación de investigadores ni a pagar los elevados costos de la analítica complementaria a la Arqueología. Frente a esa restricción de las subvenciones a la 'Arqueología de investigación', la Administración prima a la llamada 'Arqueología de intervención' (o 'de urgencia') poniendo a su disposición presupuestos muy elevados (francamente abusivos en bastantes casos) sin preocuparse demasiado por controlar la calidad del trabajo desarrollado ni sus resultados científicos.

Al contrario de lo que ahora caracteriza la investigación de la Prehistoria en Navarra, Alava, Guipúzcoa y Vizcaya, en las provincias vascas del norte del Pirineo, por diversas causas (de carácter legislativo y administrativo, entre otras), sigue siendo la iniciativa individual quien mantiene el desarrollo de la mayor parte de las investigaciones de campo, requiriendo una admirable dedicación a quienes las llevan adelante, con gran penuria de medios humanos, de equipamiento y económicos.

El conjunto de datos e interpretaciones que hoy tenemos sobre el pasado prehistórico de este territorio se ha ido constituyendo a lo largo de cerca de un siglo de investigaciones. El panorama histórico que con ellos se puede esbozar, desde el Paleolítico inferior hasta el inicio de la Edad Antigua, no es uniforme: mientras que al conocimiento de algunos períodos y situaciones culturales se ha dedicado un esfuerzo especial (mediante excavaciones reiteradas y el estudio sistemático de sus restos, según el interés y la preparación específica de los investigadores) de otros aún se sabe muy poco.

J.M. de Barandiarán (en equipo con Aranzadi y Eguren entre 1917 y 1936 y solo hasta inicios de los 70) descubrió y excavó bastantes dólmenes en Alava, en Guipúzcoa y en las zonas próximas de Navarra y muy

\footnotetext{
logía Navarra" patrocinada por la Institución Príncipe de Viana de su Gobierno Foral, mientras que los correspondientes en Vitoria de la revista "Boletín de la Institución Sancho El Sabio" desde 1957 han pasado a "Estudios de Arqueología Alavesa" del Instituto Alavés de Arqueología desde 1966 (añadiéndose hoy, en el panorama de las publicaciones específicas de Álava, la segunda época del "Boletín..." desde 1991, y el proyecto de una serie de monografías sobre yacimientos que su Diputación Foral está ahora perfilando).

El noticiario regular de las actuaciones de campo de cada año (excavaciones y prospecciones) se produce en dos publicaciones: en el anuario "Arkeoikuska" que el Gobierno Vasco edita en Vitoria desde 1981, dando noticia de lo actuado con subvenciones de la Administración pública en Alava, Vizcaya y Guipúzcoa; y en la revista "Trabajos de Arqueología Navarra" que incluye, desde su volumen 7 de 1988, una sección de 'Actividades Arqueológicas en Navarra' con la reseña preliminar de ese tipo de trabajos en Navarra.

En cuanto al desarrollo de congresos de intercambio de informaciones, entre otras convocatorias se pueden recordar la cuarta de los Symposia de Prehistoria Peninsular que se dedicó integramente al estudio de la Prehistoria y Antropología vascas (en Pamplona, en 1964), las Jornadas de Antropología (organizadas por la Societé d'Anthropologie du Sud-Ouest y la Sociedad de Estudios Vascos, en Bayona y San Sebastián, en 1981), las sesiones del II Congreso Mundial Vasco (en Vitoria, en 1987), las dos convocatorias ya celebradas del Congreso General de Historia de Navarra (de 1986 y 1990), varios de los Cursos de Verano de la Universidad del País Vasco (en San Sebastián), o la reunión "The Late Quaternary in the Western Pyrenean Region" (en Vitoria, de 1990).
} 
pocos en Vizcaya e investigó a fondo un lote muy significativo de cuevas habitadas en el Paleolítico medio y superior y en el Aziliense en Vizcaya y Guipúzcoa. Bastante menos intensa fue su contribución al conocimiento de otras etapas, aunque esbozara los primeros mapas de distribución territorial de sus yacimientos.

En los veinte últimos años el impulso de nuevos grupos de arqueólogos ha abordado la investigación de cuevas de enterramiento y de habitación de la Prehistoria reciente (Neolítico, Calcolítico y Edad del Bronce), sobre todo en Vizcaya y Alava, y del poblamiento al aire libre, especialmente en Navarra y Alava. Es muy importante también la aportación de los yacimientos de Guipúzcoa, Alava y Navarra ahora en excavación para el conocimiento de los modos de vida de las poblaciones del Paleolítico superior y del Mesolítico (como Aitzbitarte III, Arrillor, Abauntz, Berroberría o Aizpea); y destaca la promoción de excavaciones sistemáticas en megalitos del Neolítico avanzado al Bronce y en poblados de la Edad del Hierro en bastantes zonas.

En fin, podemos asegurar que las investigaciones de J.M.de Barandiarán, excelentes en el contexto de su época, se prolongan hoy, con un interés y un método sustancialmente inspirados en su obra y con una lógica intensidad mayor, potenciada por las posibilidades de equipos, técnicas y presupuestos mejor dotados que los que él tuvo a su disposición.

En sus casi 102 años de edad J.M.de Barandiarán ha dejado, como hombre, el recuerdo de su talante comprensivo y bondadoso y, en su obra, una aportación científica extensa y riquísima de contenido. "Más que un teórico de atisbos geniales, ha sido siempre un hombre práctico, sin concesiones a la galería. La brillantez calculada y efectista sucumbe en él y se difumina, en función de la claridad ascética de sus argumentos, sólidamente cimentados en el aparato crítico ... Lo que cuenta en él - a veces con rudeza esquemática - no es la figura retórica, sino el dato mismo, del que se constituye en apasionado detector, primero; y a partir de ese momento, en fiel transmisor" (Satrústegui 1980: 15-16).

\section{EN CONCLUSIÓN}

Tres áreas de la Prehistoria deben a la obra de J.M.de Barandiarán una aportación sustancial: las cuevas habitadas en el Paleolítico medio y superior, los depósitos funerarios en dólmenes del Neolítico avanzado y Calcolítico y el fenómeno de los círculos de incineración ('cromlech' o baratzak) pirenaicos de la Edad del Hierro. De sus técnicas de excavación y recogida de informaciones arqueológicas se debe asegurar, como antes advertíamos, que resultan ejemplares para lo que en su tiempo, sea en la primera etapa (de 1917 a 1936) de sus trabajos o en la segunda (de 1954 a comienzos de los 70), se hacía.

Es inexcusable el valor de las referencias que J.M.de Barandiarán recuperó y ejemplar su actitud personal científica y humana, como investigador que se aproximó al conocimiento a través de unos datos que buscó con tenacidad y asumió siempre con cierto escepticismo. Su obra y actitudes intelectuales, como maestro directo de la generación de los 60 y mediato de los grupos posteriores, hallan su continuidad en la 'escuela' dilatada que engloba a la mayoría de los equipos que ahora han asumido y llevan adelante la empresa del conocimiento arqueológico de la Prehistoria vasca.

Son frecuentes en la última década los balances historiográficos que recuerdan actuaciones y valoran equipos, resultados e intenciones de la Prehistoria de la Península Ibérica: se han empezado a convocar algunas reuniones (como las dos ya tenidas sobre el progreso del conocimiento) y se están publicando varias reflexiones sobre orientación y teorías ${ }^{17}$. En esa línea de consideración he intentado señalar en estas notas lo

17. Entre quienes han atendido en particular a la historiografía de la Prehistoria cantábrica son de obvia referencia ejemplar las documentadas aportaciones de B.Madariaga de la Campa (Hermilio Alcalde del Río. Una Escuela de Prehistoria 
que los estudios de J.M.de Barandiarán sobre la Prehistoria de esta parte del sur de Europa han significado y tienen de validez.

El norte de la Península Ibérica, zona pionera en las investigaciones de Prehistoria peninsular, posee una tradición bien asentada de estos estudios y una amplia serie de museos y de yacimientos visitables. Algunas evaluaciones recientes de la investigación del Paleolítico superior en este extenso territorio parecen reducir, con un juicio excesivamente simplificador, todo lo genéricamente cantábrico (el conjunto del 'litoral' o 'región' cantábrica, desde la Navarra atlántica a Asturias: entre el Nivelle o Bidasoa al Nalón) a lo acaecido en la provincia de Cantabria (=Santander). Por amistad (comprensible) en unos casos y por desconocimiento (no excusable) en otros, algunas actuaciones de investigación (normalmente las que mejor se aprecian desde la 'escuela de Madrid' - es decir por prehistoriadores y grupos de trabajo procedentes o formados en sus Universidades o en el Instituto de Prehistoria del CSIC - y producidas en la provincia de Santander) parecen ser las únicas, silenciándose o minusvalorándose otros 'protagonismos' (en investigadores, equipos, estudios o yacimientos de las restantes provincias de la región). Así se ha otorgado una excepcional importancia a la excavación del buen yacimiento de la cueva Morín y a la influencia del prestigioso Institut du Quaternaire de la Universidad de Burdeos y de alguna otra institución francesa enfatizando su papel en la renovación sustancial y configuración actual del conjunto de la Prehistoria cantábrica ${ }^{18}$.

Desde el conocimiento más inmediato de lo que, tan bien y a menudo, se ha hecho por el Paleolítico en la provincia de Cantabria se elevan calificaciones generalizadas al resto de las provincias que responden a tópicos que se deben matizar. Aceptando, lógicamente, que lo que ahí se afirma es exacto (pero no completo), el

toria en Santander, Publicaciones del Patronato de las Cuevas Prehistóricas de la Provincia de Santander, Santander 1972) o de M.C.Márquez Uría (El Conde de la Vega del Sella: su obra científica. Memoria de Licenciatura, Universidad de Oviedo, 1974). Mientras que, entre otros textos muy recientes, por sus reflexiones sobre tendencias y su evaluación general del conjunto de la Prehistoria peninsular se deben citar los de J. Arce y R. Olmos (editores de Historiografía de la Arqueología y de la Historia Antigua en España (siglos XVIII-XX). Ministerio de Cultura, Madrid 1991), M.R.González Morales ('La justification archéologique des origines régionales dans l'Espagne des communautés autonomes', Racines 1991: 15-27), J.M. Vázquez Varela y R.Risch ('Theory in Spanish archaeology since 1960' in Archaeological theory in Europe: the last three decads, ed. I. Hodder: 25-5. Routledge, Londres 1991) o M.Díaz Andreu ('Theory and ideology in archaeology: Spanish archaeology under the Franco régime'. Antiquity 67: 74-82, 1993). Por otra parte deben recordarse las reuniones específicas organizadas por el Centro de Estudios Históricos del C.S.I.C.:'I Congreso de Historiografía de la Arqueología y la Historia Antigua en España (siglos XVIII-XX)" (en Madrid 1988) y "II Congreso de Historiografía de la Arqueología en España (siglos XVIII-XX)" (en Madrid 1995).

18. Así especialmente se ha insistido en la gran importancia que tuvo para el desarrollo o la renovación de los estudios del Paleolítico en el norte de la Península el influjo de algunos investigadores extranjeros: para M.I. Martínez Navarrete (Una revisión crítica de la prehistoria española: la Edad del Bronce como paradigma. Siglo Veintiuno de España Editores, Madrid 1989: 70) “...en el caso de las cuevas y abrigos es fundamental la conexión de los paleolitistas cantábricos con los franceses vía el Instituto del Cuaternario de la Universidad de Burdeos o vía el Museo del Hombre de Paris, dirigidos por los doctores Bordes $(+)$ y Leroi-Gourhan $(+)$, respectivamente. Con esta última institución y, en concreto, con su Laboratorio de Palinología, dirigido por madame Arl, Leroi-Goruhan se vincula la línea más continuada e influyente de estudios en ese campo en la Península (P. López García, Departamento de Prehistoria, CSIC, Madrid)" mientras que A. Moure y M. Santonja (en 'La renovación de los estudios sobre Paleolítico en los últimos veinte años', Boletín de la Asociación de Amigos de la Arqueología 30-31, 1991 (pp.13-25): 16 y 20) opinan que "en la incorporación de nuevas técnicas jugaron un papel no desdeñable varios investigadores extranjeros. Entre ellos resulta necesario señalar a L.G. Freeman y sus trabajos en el Paleolítico MedioSuperior de Cueva Morín. Las excavaciones en este yacimiento cantábrico supusieron en su momento y en varios sentidos una auténtica renovación (equipo multidisciplinar, técnicas de excavación y registro, procedimientos de clasificación de laboratorio, etc.) que tuvo amplio eco en la generación de investigadores que entonces comenzaba su labor". 
juicio que el no bien enterado extraerá de ello puede ser muy parcial: conviene, pues, recordar algo tan obvio como que:

- a, el conjunto del territorio cantábrico excede en mucho por Oeste (Asturias) y Este (Vizcaya,Guipúzcoa y Navarra) los límites provinciales estrictos de la provincia epónima.

- $b$, en estas otras provincias (y en la misma de Cantabria) hay equipos de trabajo que abordan, con excelente metodología no adoptada simplemente de aquel influjo extranjero concreto, el estudio de importantes yacimientos, cuyas aportaciones no parecen tan bien conocidas y, por tanto, no son suficientemente utilizadas en varias revisiones de conjunto publicadas hace poco (p.e. en algunos manuales de Prehistoria destinados a un público universitario).

- c, que la importancia del influjo sobre la Prehistoria cantábrica de algunos especialistas extranjeros debe ser acotada a sus límites precisos. La mayoría de cuantos trabajamos en los últimos 25 años en la Prehistoria (Paleolítico medio y superior, Mesolítico, etc.) de esta extensa región hemos sido suficientemente eclécticos como para saber acoger, adaptar o rechazar planteamientos teóricos y propuestas concretas de intervención vengan de donde vinieren. No todos hemos debido aprender precisamente ni sólo de la excavación de Morín o de las aportaciones de F.Bordes, de D.de Sonneville Bordes o de L.G.Freeman (aunque hayamos mantenido excelentes relaciones de amistad y cooperación científica con ellos) ni la depuración en los sistemas de recogida de datos (p.e. inventarios sistemáticos, excavación mediante coordenadas cartesianas, cartografía espacial integral o utilización del teodolito, analítica de los tecnocomplejos) han de ser atribuidas exclusivamente al influjo de aquellas concretas 'escuelas' bordelesa o americana. Otros muchos 'maestros' (como J.M.de Barandiarán, F.Jordá, J.Tixier o G.Laplace entre otros) han influido tan decisivamente como aquéllos en bastantes de quienes estamos ahora trabajando en el norte de la Península Ibérica.

Por otra parte, en estos años últimos y con cierta frecuencia se reitera la necesidad que tiene la Arqueología de renovar métodos y preocupaciones ${ }^{19}$. Bastantes de esas referencias críticas señalan atinadamente excesos o insuficiencias de lo bastante hasta ahora actuado. Pero también las hay ligeras, impertinentes o injustas: pues, sin mucho conocimiento del fondo argumental evaluado, se extienden indiscriminadamente a casi todo

19. Como ejemplo de la argumentación sobre la deseada renovación de la Prehistoria del norte peninsular y de la orientación que habrá de adoptar me sirven un par de textos recientes ('Los orígenes de las economías de producción en el País Vasco meridional: de la descripción a la explicación', Ilunzar 94, 1993, pp. 87-99 por J.García; y 'El Neolítico de la región Cantábrica. Nuevas perspectivas' I ${ }^{o}$ Congresso de Arqueologia Peninsular, Actas III 1994, pp. 91-118, por P.Arias) que, como tantos, especialmente preocupados por avanzar (con 'nuevas perspectivas' y superando 'fases' del conocimiento) resaltan las diferencias que perciben entre lo que normalmente se hizo hasta ahora (que les parece haber sido insuficiente o esterilizador, por meramente descriptivo o 'arqueográfico') y lo que se propone (que es considerado 'enriquecedor' porque aborda la interpretación en una 'reconstrucción histórica'). Así "se ha conseguido una "base de datos" que habría que ir completando ... puede afirmarse que nos encontramos en una fase descriptiva, cuyo objetivo ha sido, y debe seguir siendo, la búsqueda y descripción de hechos a través de los medios que la Arqueología y disciplinas auxiliares ponen a nuestro alcance ... a nuestro parecer, junto a la fase descriptiva en la que se ha de continuar incidiendo, sería conveniente iniciar una Fase de Explicación que, al menos, cree un marco de discusión del que surjan propuestas que necesariamente enriquecerán el conocimiento alcanzado hasta la fecha ... proponemos al amparo de los datos actuales, sin duda insuficientes, un modelo de explicación al proceso..." (op.cit de J. García 1993, pp. 88 a 90); o "No menos importante es continuar con la renovación teórica mencionada más arriba. En particular queremos llamar la atención sobre la necesidad de hacer compatible el rigor en el análisis de la información con su utilización para una reconstrucción histórica, en el más rico sentido del término. Aunque no siempre es fácil hacer historia a partir de la arqueología, hemos de huir de los falsamente objetivos planteamientos arqueográficos que tanto han esterilizado nuestra tradición investigadora durante muchos años" (op.cit. de P.Arias 1994, pp.108-109). 
lo precedente (acaso por el hecho de serlo) o deciden por la renovación a ultranza de perspectivas, intentando superar fases del conocimiento hacia la necesaria depuración del saber en Prehistoria.

En un balance final, se puede asegurar que es general hoy entre la mayoría de los prehistoriadores de la región cantábrica el cuidado por la recogida y el análisis exhaustivo de los datos; se considera imprescindible la práctica de la excavación sistemática y el incremento de secuencias estratigráficas bien contextualizadas. Buena parte de los prehistoriadores que ahora trabajan en esta región intenta que las impresiones no sustituyan a los datos, la tertulia al trabajo, el prejuicio a la idea, las doctrinas a los hechos, o el marketing y la promoción curricular a la búsqueda del saber. Todavía siguen siendo aquí más los especialistas en el trabajo de campo que los 'especialistas en congresos' (¡tantos que topifican o generalizan sobre lo hecho o escrito por otros, no aportando datos ni revisiones críticas más sólidas que lo anteriormente recuperado!).

En la inútil querella entre los que se califican a sí mismos de 'arqueólogos' (los que se constituyen en debeladores sistemáticos de tantos presuntos excesos y desvíos precedentes) y 'arqueógrafos' (casi todos los demás) no se ha de olvidar la advertencia de uno de los viejos maestros de la Nueva Arqueología, David Clarke, sobre la importancia de una correcta recuperación de los datos (los hechos) con sus atributos (de quienes habrá que decidir su pertinencia) como paso previo imprescindible a cualquier posterior reconstrucción de las informaciones. En esta línea se mantuvo toda la investigación de campo de J.M.de Barandiarán durante casi medio siglo de progreso de la Prehistoria del Pirineo vasco, con un rigor científico ejemplar y unos resultados que resultan hoy mismo de imprescindibles reconocimiento y uso.

\section{BIBLIOGRAFÍA}

ABERG, N. (1921): La civilisation énéolithique dans la Péninsule Ibérique. Arboten Utgifna med Understöd af Vilhelm Ekmans Universitetsfund 25, Uppsala.

ALTUNA, J. (1972): Fauna de mamíferos de los yacimientos prehistóricos de Guipúzcoa. Con Catálogo de los Mamíferos Cuaternarios del Cantábrico y del Pirineo Occidental. Munibe vol. 24, San Sebastián.

ALTUNA, J.; ARMENDARIZ, A.; BARRIO, L.; ETXEBERRIA, F;; MARIEZKURRENA, K.; PEÑALVER, J.; ZUMALABE, F.J. (1990): Gipuzkoa. /K/Clarta Ar/k/quleologi/ko/c/a. I. Megalitolak/s. Munibe Suplemento $\mathrm{n}^{\mathrm{Q}} 7$, San Sebastián.

APELLANIZ, J.M. (1974): El grupo de Los Husos durante la Prehistoria con cerámica en el País Vasco. Estudios de Arqueología Alavesa vol.VII, Vitoria.

ARANZADI, T. de; BARANDIARÁN, J.M. de (1928): Exploraciones prehistóricas en Guipúzcoa en los años 1924 a 1927. Cavernas de Ermittia (Sasiola), Arbil (Lastur) y Olatzazpi (Asteasu), dolmen de Basagain (Murumendi) y caverna de Irurixo (Vergara). Ed.Diputación de Guipúzcoa, San Sebastián.

- (1935): Exploraciones de la caverna de Santimamiñe (Basondo: Cortézubi). 3. Exploraciones en la caverna de Lumentxa (Lequeitio). Ed.Diputación de Vizcaya, Bilbao.

- (1919): Exploración de nueve dólmenes del Aralar guipuzcoano. Ed.Diputación de Guipúzcoa, San Sebastián.

- (1925: Exploraciones de la caverna de Santimamiñe (Basondo-Cortézubi). I. Figuras rupestres. Ed.Diputación de Vizcaya, Bilbao.

BARANDIARÁN, J.M. de (1917): Discurso leído en la solemne apertura del Curso Académico de 1917/1918 en el Seminario Conciliar de Vitoria. Boletín Oficial del Obispado de Vitoria, pp. 503-506, 515-525, 540548.

- (1919): Prehistoria. Primer Congreso de Estudios Vascos, pp.333-363, Bilbaína de Artes Gráficas, Bilbao.

- (1931): Breve Historia del Hombre Primitivo. Anuario de Eusko-Folklore vol. XI.2a parte, Vitoria.

- (1932): Apuntes de Geología general y de la del País Vasco. Imprenta del Montepío Diocesano, Vitoria. 
BARANDIARÁN, J.M. de (1934): El hombre primitivo en el País Vasco. Col. Zabalkundea n.ำ 3, San Sebastián. BARANDIARÁN, L. de (1951): "De mis recuerdos de Aranzadi". Munibe 3, pp. 84- 93.

- (1976): José Miguel de Barandiarán, patriarca de la cultura vasca. Ed.Caja de Ahorros Municipal, San Sebastián.

- (1989): Cartas a José Miguel de Barandiarán. (Primera etapa, 1915- 1936). Ed.Caja de Ahorros Municipal, San Sebastián.

- (1995): Cartas a José Miguel de Barandiarán. (Segunda etapa, 1952-1991). Fundación Kutxa, San Sebastián.

BARANDIARÁN, I. (1967): El Paleomesolítico del Pirineo Occidental. Bases para una sistematización tipológica del instrumental óseo paleolítico. Monografías Arqueológicas vol.3, Zaragoza.

- (1980): "D. José Miguel de Barandiarán, prehistoriador del pueblo vasco". Páginas de Historia del País Vasco, pp.23-30. EUNSA, Pamplona.

- (1988): Prehistoria. Paleolítico. Historia General de Euskalerria. Ed. Auñamendi, San Sebastián.

- (1992): "A la memoria de José Miguel de Barandiarán". Trabajos de Arqueología Navarra 10, pp. 9-14.

BOSCH GIMPERA. P. (1923): El problema etnológico vasco y la Arqueología. Revue Internationale des Etudes Basques XIV, pp. 589-660.

CASTILLO, A. del (1928): La Cultura del Vaso Campaniforme. (Su origen y extensión en Europa). Universidad de Barcelona, Barcelona.

ELOSEGUI, J. (1948): "Pequeño ensayo sobre la Prehistoria y Paleontología del Cuaternario de Guipúzcoa y sus materiales de estudio". Ikuska nº 8-9, pp. 185-192 y 41-60.

MADARIAGA DE LA CAMPA, B. (1975): "Historia de los descubrimientos prehistóricos". La Prehistoria de la Cornisa Cantábrica, pp.11-32, Institución Cultural de Cantabria, Santander.

MANTEROLA, A. (1984): “La escuela vasca de Etnología. Barandiarán, testigo excepcional”. La Etnia Vasca. Euskaldunak vol.4, pp.25-158, Ed.Etor, San Sebastián.

MÁRQUEZ, M.C. (1974a): El Conde de la Vega del Sella: su obra científica. Memoria de Licenciatura mecanografiada. Universidad de Oviedo.

- (1974b): "Trabajos de campo realizados por el Conde de la Vega del Sella". Boletín del Instituto de Estudios Asturianos 83, pp. 811-835.

MUJIKA, J.A. (1985): "Euskal Historiaurrearen Historiografia". Euskal Herriaren Historiaz II. Historiaurrea, pp.19-39, Argitarapen Zerbitzua Euskal Herriko Unibertsitatea, Bilbao.

OBERMAIER, H. (1925): El Hombre Fósil. Memoria no 9 de la Comisión de Investigaciones Paleontológicas y Prehistóricas, Museo Nacional de Ciencias Naturales, Madrid.

OBERMAIER, H.; VEGA DEL SELLA, C. de la (1918): La cueva del Buxu (Asturias). Memoria $\mathbf{n}^{0} 20$ de la Comisión de Investigaciones Paleontológicas y Prehistóricas, Museo Nacional de Ciencias Naturales, Madrid.

PERICOT, L. (1950): Los Sepulcros Megalíticos Catalanes y la Cultura Pirenaica. Monografías del Instituto de Estudios Pirenaicos n. ${ }^{\circ}$ 31, Barcelona.

— (1968): "La investigación del Paleolítico Superior en España". Indice Histórico Español 1964, vol. X pp. XI-XXXII.

SATRUSTEGUI, J.M. (1980): “D. José Miguel de Barandiarán: el etnólogo y hombre”. Páginas de Historia del País Vasco, pp. 13-22. EUNSA, Pamplona.

VALLESPÍ, E. (1966): "Las investigaciones prehistóricas en la provincia de Alava". Estudios de Arqueología Alavesa no $^{1}$, pp. 7-26.

- (1975): "Investigación de la Prehistoria navarra. Historiografía y Bibliografía". Príncipe de Viana no 138139, pp.47-81. 
VEGA DEL SELLA, C. de la (1930): Las cuevas de la Riera y Balmori (Asturias). Memoria n.․ 38 de la Comisión de Investigaciones Paleontológicas y Prehistóricas, Museo Nacional de Ciencias Naturales, Madrid.

V.V.A.A. (1964): Homenaje a don José Miguel de Barandiarán. 2 vols. Publicaciones de la Excma. Diputación de Vizcaya, Bilbao.

- (1971): Munibe vol.23. Sociedad de Ciencias Aranzadi, San Sebastián.

- (1978): Estudios de Arqueología Alavesa. Tomo IX. Homenaje a D. José Miguel de Barandiarán. Diputación Foral de Alava, Consejo de Cultura, Vitoria.

- (1979): José Miguel Barandiaran-eri Omenaldia. Eusko Ikaskuntza/Sociedad de Estudios Vascos, Oñati.

- (1980): Páginas de Historia del País Vasco. Homenaje de la Universidad de Navarra a D,José Miguel de Barandiarán (abril-mayo 1977). EUNSA, Pamplona.

- (1990): Munibe vol.42. Homenaje a J.M.de Barandiarán. Sociedad de Ciencias Aranzadi, San Sebastián.

- (1992): J.M.de Barandiarán. Primer aniversario. Monográfico de la revista Muga no 83, San Sebastián. 